\title{
Application of mobile aerosol and trace gas measurements for the investigation of megacity air pollution emissions: the Paris metropolitan area
}

\author{
S.-L. von der Weiden-Reinmüller ${ }^{1}$, F. Drewnick ${ }^{1}$, M. Crippa ${ }^{2,}{ }^{*}$, A. S. H. Prévôt ${ }^{2}$, F. Meleux ${ }^{3}$, U. Baltensperger ${ }^{2}$, \\ M. Beekmann ${ }^{4}$, and S. Borrmann ${ }^{1,5}$ \\ ${ }^{1}$ Particle Chemistry Department, Max Planck Institute for Chemistry, Mainz, Germany \\ ${ }^{2}$ Laboratory of Atmospheric Chemistry, Paul Scherrer Institute, Villigen, Switzerland \\ ${ }^{3}$ Institut National de 1'Environnement Industriel et des Risques, Verneuil en Halatte, France \\ ${ }^{4}$ Laboratoire inter-universitaire des Systèmes Atmosphériques, UMR7583 - CNRS, Université Paris Est Créteil et Université \\ Paris Diderot, France \\ ${ }^{5}$ Institute of Physics of the Atmosphere, Johannes Gutenberg University Mainz, Mainz, Germany \\ *now at: European Commission Joint Research Centre, Institute for Environment and Sustainability, Ispra, Italy
}

Correspondence to: F. Drewnick (frank.drewnick@mpic.de)

Received: 6 August 2013 - Published in Atmos. Meas. Tech. Discuss.: 22 August 2013

Revised: 22 November 2013 - Accepted: 9 December 2013 - Published: 28 January 2014

\begin{abstract}
For the investigation of megacity emission development and the impact outside the source region, mobile aerosol and trace gas measurements were carried out in the Paris metropolitan area between 1 July and 31 July 2009 (summer conditions) and 15 January and 15 February 2010 (winter conditions) in the framework of the European Union FP7 MEGAPOLI project. Two mobile laboratories, MoLa and MOSQUITA, were deployed, and here an overview of these measurements and an investigation of the applicability of such measurements for the analysis of megacity emissions are presented. Both laboratories measured physical and chemical properties of fine and ultrafine aerosol particles as well as gas phase constituents of relevance for urban pollution scenarios. The applied measurement strategies include cross-section measurements for the investigation of plume structure and quasi-Lagrangian measurements axially along the flow of the city's pollution plume to study plume aging processes. Results of intercomparison measurements between the two mobile laboratories represent the adopted data quality assurance procedures. Most of the compared measurement devices show sufficient agreement for combined data analysis. For the removal of data contaminated by local pollution emissions a video tape analysis method was applied. Analysis tools like positive matrix
\end{abstract}

factorization and peak integration by key analysis applied to high-resolution time-of-flight aerosol mass spectrometer data are used for in-depth data analysis of the organic particulate matter. Several examples, including a combination of MoLa and MOSQUITA measurements on a cross section through the Paris emission plume, are provided to demonstrate how such mobile measurements can be used to investigate the emissions of a megacity. A critical discussion of advantages and limitations of mobile measurements for the investigation of megacity emissions completes this work.

\section{Introduction}

A growing fraction of the world's population is living in cities or large urban agglomerations of increasing size. In 2008 more than $50 \%$ of the human beings lived in an urban environment. Considering the actual world's population of more than 7 billion people (United Nations, 2013), this leads to a huge concentration of activities within a relatively small area. The number of so-called megacities, defined as metropolitan areas with more than 10 million inhabitants (Molina and Molina, 2004), grew from 2 in 1970 to 23 in 2011. It is predicted that in 2025 about 37 cities worldwide 
will classify as megacities (United Nations, 2012). Along with major challenges as urban planning, industrial development and transportation these intense pollution hot-spots cause a number of scientific questions concerning their influence on local and regional air quality, with its impact on human health, flora and fauna as well as atmospheric chemistry and climate (e.g. Kunkel et al., 2012).

In Europe the metropolitan areas of London, Paris, the Rhine-Ruhr and the Po valley regions, Moscow and Istanbul are classified as megacities. Within the framework of the European Union FP7 MEGAPOLI project (Megacities: Emissions, urban, regional and Global Atmospheric POLlution and climate effects, and Integrated tools for assessment and mitigation; MEGAPOLI Project, 2013) two major field campaigns were carried out in the greater Paris region in summer 2009 and winter 2010. The focus of these measurement campaigns was to characterise the Paris emission plume with respect to trace gases (e.g. $\mathrm{O}_{3}, \mathrm{SO}_{2}, \mathrm{NO}_{\mathrm{x}}, \mathrm{CO}_{2}$ ) and aerosol particles in the size range from a few nanometers to several micrometers including chemical composition. The overall goal was to assess its impact on the local and regional air quality and to investigate aerosol transformation processes within this plume as it travels away from its source. This includes the influence of meteorology on the emission plume due to different environmental conditions in summer and winter.

Typically, aerosol and trace gas measurements are performed at stationary sites what leads to a strong spatial limitation of the data and dependency on peculiarities of the chosen location. Especially for the investigation of emissions from spatially extended aerosol sources like cities and formation and transformation of particles during transport, stationary measurements are only suitable to a limited extent. For this purpose, in the past few years several ground-based mobile laboratories equipped with high-time resolution instrumentation have been developed which allow measurements with large spatial flexibility (Bukowiecki et al., 2002; Kolb et al., 2004; Pirjola et al., 2004; Drewnick et al., 2012). These ground-based mobile laboratories installed on vehicles are an expedient addition to research aircraft and laboratories installed on ships.

Here we focus on mobile ground-based measurements of aerosol and trace gas characteristics that were carried out during both campaigns by two research groups with two different mobile aerosol laboratories. These mobile measurements were embedded in a network of stationary groundbased, additional mobile ground-based remote sensing and aircraft measurements, satellite observations and local, regional and global modelling (Beekmann et al., 2014). To integrate the presented measurements in a greater context of urban pollution investigations (e.g. in Barcelona, Beijing, Mexico City, Nashville, Paris, West Midlands, UK) we refer to the comprehensive number of publications focused on this topic (e.g. Nunnermacker et al., 1998; McMurry, 2000; Raga et al., 2001; Seakins et al., 2002; Harrison et al., 2006; Gros et al., 2007; Pey et al., 2008; Elanskii et al., 2010; Mohr et al., 2012; Crippa et al., 2013; Freutel et al., 2013).

The measured parameters of both mobile laboratories include concentrations of gas phase $\mathrm{O}_{3}, \mathrm{NO}_{\mathrm{x}}$ and $\mathrm{CO}_{2}$, aerosol particle number concentration, size distribution and chemical composition as well as meteorological parameters (wind direction, relative humidity, pressure and temperature). For the measurement of the sub-micron particle chemical composition on-line measurement devices such as the aerosol mass spectrometer (Jayne et al., 2000; DeCarlo et al., 2006; Lanz et al., 2010) have been deployed and adopted for the mobile measurements. In combination with complex analysis tools as positive matrix factorization (PMF) (Paatero and Tapper, 1994; Paatero, 1997; Lanz et al., 2007; Ulbrich et al., 2009) and peak integration by key analysis (PIKA) (ToFAMS Analysis Software Homepage, 2013) a large amount of information can be obtained about aerosol chemical composition (Zhang et al., 2005; Canagaratna et al., 2007; Sun et al., 2010; Zhang et al., 2011). The measurement of carbon dioxide, ozone and nitrogen oxides together with meteorological parameters is needed for numerical simulation of the urban atmospheric chemistry (e.g. Fenger, 1999; Akimoto, 2003; Crutzen, 2004; Gurjar and Lelieveld, 2005).

The purpose of this paper is to discuss the general applicability of the developed and deployed measurement and analysis strategies for urban emission investigations using the MEGAPOLI data base as example. In Sect. 2 we provide an overview of the MEGAPOLI field campaigns and describe the two mobile laboratories including specification and intercomparison of the on-board instruments, as well as different measurement strategies. A general overview of the advanced data preparation for analysis completes this section. In Sect. 3 four examples of mobile measurements are presented that investigate the differences between long-range transported and locally produced pollution. A combination of data from both mobile laboratories allows a detailed view of the spatial structure of the emission plume. Axial measurement trips show the spatial extent of the emission plume, while a final example of stationary measurements at various locations around the city illustrates the influence of the Paris emission plume on local air quality. These measurement examples demonstrate the successful application of the individual measurement strategies. Section 4 provides a critical discussion of possibilities, challenges and limitations of mobile measurements.

\section{Methods}

\subsection{MEGAPOLI field campaigns}

MEGAPOLI project: the European Union FP7 MEGAPOLI project (MEGAPOLI Project, 2013) is a collaborative project to assess impacts of megacities and large air-pollution hotspots on local, regional, and global air quality and climate. 
An additional goal is the quantification of feedbacks between megacity emissions, air quality, local and regional climate, and global climate change. Based on new findings improved, integrated tools are to be developed and implemented in existing air quality models to assess the impacts of air pollution from megacities on regional and global air quality and climate and to evaluate the effectiveness of mitigation strategies.

MEGAPOLI field campaigns: two major field campaigns took place in the greater Paris region in France, which is classified as megacity with currently about 10.6 million inhabitants (United Nations, 2012). The greater Paris metropolitan area, defined as the territory with high residential density and additional surrounding areas that are also influenced by the city, for example by frequent transport or road linkages (United Nations, 2012), has actually a population of more than 12 million inhabitants (Aire urbaine, 2013). The summer measurement period was carried out between 1 July and 31 July 2009, the winter field campaign between 15 January and 15 February 2010. The main objective of these field measurements was to characterise and quantify sources of primary and secondary aerosol in and around a large agglomeration and to investigate its evolution and impacts on local and regional air quality as well as atmospheric chemistry in the megacity emission plume. Three groundbased stationary measurement sites were operated - two suburb and one downtown sites (for details see MEGAPOLI project, 2013; Freutel et al., 2013; Crippa et al., 2013). Mobile measurements were carried out by a research aircraft (applying an ATR42 in summer and a Piper Aztec in winter, SAFIRE, 2013), remote-sensing mobile laboratories (DOAS instrument operated on top of a regular passenger vehicle, a LIDAR instrument installed on a pick-up truck, Royer et al., 2011) and the two mobile aerosol research laboratories MoLa and MOSQUITA. These mobile laboratories measured while driving through atmospheric background and emission plume influenced air masses, carried out several stationary measurements at various places in and around Paris and were also used for intercomparison studies with the stationary measurement sites and the research aircraft.

\subsection{Mobile laboratories and on-board instrumentation}

\subsubsection{Mobile laboratory "MoLa"}

Platform: the Max Planck Institute for Chemistry in Mainz, Germany, developed a compact Mobile aerosol research Laboratory ("MoLa") based on a Ford Transit delivery vehicle for stationary and mobile measurements of aerosol physical and chemical properties and trace gas concentrations (Drewnick et al., 2012). The main inlet system for mobile measurements is located above the driver's cabin at a height of approximately $2.2 \mathrm{~m}$ and it is equipped with a nozzle optimised for an average driving velocity of about $50 \mathrm{~km} \mathrm{~h}^{-1}$. Stationary measurements are performed using an extendable inlet (up to $10 \mathrm{~m}$ ) on the roof of the vehicle for aerosol sampling. A specific feature of the MoLa aerosol inlet system is its optimisation for minimal sampling and transport losses using the Particle Loss Calculator (von der Weiden et al., 2009). The residence time of the aerosol during its way through the inlet system to the individual instruments was measured and calculated for sampling time correction and the occurring - but negligible - particle losses were quantified (see Sect. 2.3 and Drewnick et al., 2012).

Instrumentation: Table 1 provides detailed information on the deployed instruments. During both field campaigns MoLa was equipped with a High-Resolution Time-of-Flight Aerosol Mass Spectrometer (HR-ToF-AMS; DeCarlo et al., 2006) to measure size-resolved mass concentrations of nonrefractory species approximately in the $\mathrm{PM}_{1}$ size range. Additionally, black carbon and particle-bound polycyclic aromatic hydrocarbon (PAH) mass concentrations were measured to achieve detailed chemical information about total $\mathrm{PM}_{1}$ particle composition, including most species found in the sub-micron aerosol. The aerosol total number concentration was measured as well as aerosol particle size distributions applying three different techniques (electrical mobility, aerodynamic sizing, light scattering). The detected trace gases include $\mathrm{O}_{3}, \mathrm{SO}_{2}, \mathrm{NO}, \mathrm{NO}_{2}, \mathrm{CO}, \mathrm{CO}_{2}$ and $\mathrm{H}_{2} \mathrm{O}$. Meteorological parameters like wind direction and speed, ambient pressure, temperature, relative humidity and precipitation were recorded as well as GPS vehicle position and environmental conditions (e.g. traffic situation) using a webcam.

\subsubsection{Mobile laboratory "MOSQUITA"}

Platform: the Paul Scherrer Institute in Villigen, Switzerland, developed a mobile aerosol and trace gas laboratory (Measurements Of Spatial QUantitative Imissions of Trace gases and Aerosols: "MOSQUITA"; Bukowiecki et al., 2002; Weimer et al., 2009; Mohr et al., 2011; Mobile Laboratory MOSQUITA, 2013), which utilises an IVECO Turbo Daily Transporter as platform. The main aerosol inlet is located at a height of $3.2 \mathrm{~m}$ in the front part of the vehicle allowing for isokinetic sampling at a driving velocity of $50 \mathrm{~km} \mathrm{~h}^{-1}$.

Instrumentation: Table 2 shows the equipment used in MOSQUITA. PM $_{1}$ particle chemical composition was obtained from a HR-ToF-AMS and additional black carbon mass concentration measurements. Aerosol particle concentrations were measured in total as well as size-resolved applying different techniques in summer (electrical mobility) and winter (light scattering). The recorded trace gases are $\mathrm{O}_{3}, \mathrm{NO}, \mathrm{NO}_{2}, \mathrm{CO}, \mathrm{CO}_{2}$ and $\mathrm{H}_{2} \mathrm{O}$. Meteorological parameters including wind direction, pressure, temperature, relative humidity and global radiation as well as GPS information and webcam videos complete the MOSQUITA data set. 
Table 1. Summary of measurement devices - including information about measured variables, size range, time resolution and detection limit - installed in the mobile laboratory MoLa (Max Planck Institute for Chemistry) during the summer and winter MEGAPOLI field campaigns. AMS detection limits (using the method described in Drewnick et al., 2009) were calculated for summer (S) and winter field campaign (W) separately, because the AMS detection limit can change over time.

\begin{tabular}{|c|c|c|c|c|}
\hline Measurement device & Measured variable & Size range & Time resolution & Detection limit \\
\hline $\mathrm{AMS}^{\mathrm{a}}$ & Size-resolved aerosol chemical composition & $50 \mathrm{~nm}-\sim 1 \mu \mathrm{m}$ & $1 \mathrm{~min}$ & $\begin{array}{l}\text { organics: } 0.03(\mathrm{~S}) / 0.01(\mathrm{~W}) \mu \mathrm{g} \mathrm{m}^{-3} \\
\text { nitrate: } 0.05(\mathrm{~S}) /<0.01(\mathrm{~W}) \mu \mathrm{g} \mathrm{m}^{-3} \\
\text { sulfate: }<0.01(\mathrm{~S}) / 0.01(\mathrm{~W}) \mu \mathrm{g} \mathrm{m}^{-3} \\
\text { ammonium: } 0.06(\mathrm{~S}) / 0.03(\mathrm{~W}) \mu \mathrm{g} \mathrm{m}^{-3}\end{array}$ \\
\hline MAAP ${ }^{b}$ & Black carbon mass concentration & $10 \mathrm{~nm}-1 \mu \mathrm{m}$ & $1 \mathrm{~min}$ & $0.1 \mu \mathrm{g} \mathrm{m}^{-3}$ \\
\hline $\mathrm{PAS}^{\mathrm{c}}$ & PAH mass concentration & $10 \mathrm{~nm}-1 \mu \mathrm{m}$ & $12 \mathrm{~s}$ & $1 \mathrm{ng} \mathrm{m}^{-3}$ \\
\hline $\mathrm{CPC}^{\mathrm{d}}$ & Particle number concentration & $2.5 \mathrm{~nm}-3 \mu \mathrm{m}$ & $1 \mathrm{~s}$ & N/A \\
\hline FMPS & Particle size distribution based on electrical mobility & $5.6 \mathrm{~nm}-560 \mathrm{~nm}$ (32 channels) & $1 \mathrm{~s}$ & N/A \\
\hline $\operatorname{APS}^{\mathrm{f}}$ & Particle size distribution based on aerodynamic sizing & $0.5 \mu \mathrm{m}-20 \mu \mathrm{m}(52$ channels $)$ & $1 \mathrm{~s}$ & N/A \\
\hline $\mathrm{OPC}^{\mathrm{g}}$ & Particle size distribution based on light scattering & $0.25 \mu \mathrm{m}-32 \mu \mathrm{m}$ ( 31 channels $)$ & $6 s$ & N/A \\
\hline Airpointer ${ }^{h}$ & $\mathrm{O}_{3}, \mathrm{SO}_{2}, \mathrm{CO}, \mathrm{NO}, \mathrm{NO}_{2}$ mixing ratio & N/A & $1 \mathrm{~min}$ & $\begin{array}{l}\mathrm{O}_{3}:<1.0 \mathrm{ppbV} \\
\mathrm{SO}_{2}:<1.0 \mathrm{ppbV} \\
\mathrm{CO}:<0.2 \mathrm{ppmV} \\
\mathrm{NO}_{\mathrm{x}}:<1.0 \mathrm{ppbV}\end{array}$ \\
\hline LI- $840^{\mathrm{i}}$ & $\mathrm{CO}_{2}, \mathrm{H}_{2} \mathrm{O}$ mixing ratio & N/A & $1 \mathrm{~s}$ & $\begin{array}{l}\mathrm{CO}_{2}:<1 \mathrm{ppmV} \text { (RMS noise) } \\
\mathrm{H}_{2} \mathrm{O}:<10 \text { ppmV (RMS noise) }\end{array}$ \\
\hline Meteorological Station ${ }^{\mathrm{j}}$ & $\begin{array}{l}\text { Wind speed, wind direction, temperature, precipitation, } \\
\text { pressure, relative humidity }\end{array}$ & N/A & $1 \mathrm{~s}$ & $\begin{array}{l}\text { Accuracy: } \\
\text { WindSp: } 0.3 \mathrm{~m} \mathrm{~s}^{-1} \\
\text { WindDir: } 3^{\circ} \\
\text { Temp: } 0.3^{\circ} \mathrm{C} \\
\text { RH: } 3 \% \\
\text { Precipitation: } 5 \% \\
\text { Pressure: } 0.5 \mathrm{hPa}\end{array}$ \\
\hline GPS $^{\mathrm{k}}$ & Vehicle location and speed & N/A & $1 \mathrm{~s}$ & N/A \\
\hline Webcam $^{1}$ & Driver's view through windshield & N/A & $1 \mathrm{~s}$ & N/A \\
\hline
\end{tabular}

\subsubsection{Intercomparison of corresponding measurement devices on MoLa and MOSQUITA}

Intercomparison measurements were carried out several times during both field campaigns. Not only MoLa and MOSQUITA were compared, but also both mobile laboratories with the other stationary ground-based measurement sites and the research aircraft. A detailed description of the results of these other intercomparison exercises can be found in Freutel et al. (2013) and Crippa et al. (2013).

For the two mobile laboratories the instruments (see Tables 1 and 2) measuring the following parameters were compared in this study:

- Particle number size distribution (FMPS, UHSAS, APS, OPC),

- Particle number concentration (CPC3786, CPC3010s),

- Non-refractory chemical aerosol composition (two HR-ToF-AMS),

- Black Carbon mass concentration (two MAAP),

- $\mathrm{CO}_{2}$ mixing ratio (LI-840, LI-7000),

- $\mathrm{O}_{3}$ mixing ratio (Airpointer, Ozone monitor), and
- $\mathrm{NO}_{\mathrm{x}}$ mixing ratio (Airpointer, Luminox monitor).

CO mixing ratio was not compared, because due to issues with the MoLa instrument all measurements were below detection limit during both campaigns and thus were not used for further analysis. $\mathrm{NO}$ and $\mathrm{NO}_{2}$ data are not available for MOSQUITA during the intercomparisons due to instrumental issues. The intercomparison of the MoLa weather parameters showed excellent agreement with the meteorological parameters measured at the North-East suburb measurement site (Freutel et al., 2013).

Intercomparison time periods: the intercomparison time periods during the summer campaign were 11 July 2009 from 12:05:00 until 17:39:00 (at Pontoise airport) and 23 July 2009 from 11:22:00 until 19:00:00 (at the SouthWest suburb measurement site). The winter intercomparison took place on 9 February 2010 from 11:42:00 until 19:30:00 also at the South-West suburb measurement site. All given times are in local time. For details about the mentioned measurement sites we refer to the MEGAPOLI project's website (MEGAPOLI Project, 2013) and Beekmann et al. (2014).

Particle number size distribution: during the summer field campaign both mobile laboratories applied identical FMPS devices. The measured particle number size distributions are in good agreement and the averaged size distributions during 
Table 2. Summary of measurement devices - including information about measured variables, size range, time resolution and detection limit - installed in the mobile laboratory MOSQUITA (Paul Scherrer Institute) during the summer and winter MEGAPOLI field campaigns. AMS detection limits were calculated and averaged for the two mobile measurements presented in this work $(\mathrm{S}=$ summer, $\mathrm{W}=$ winter $)$.

\begin{tabular}{|c|c|c|c|c|}
\hline Measurement device & Measured variable & Size range & Time resolution & Detection limit \\
\hline $\mathrm{AMS}^{\mathrm{a}}$ & Size-resolved aerosol chemical composition & $50 \mathrm{~nm}-\sim 1 \mu \mathrm{m}$ & $5 \mathrm{~s}(\mathrm{~S}) / 10 \mathrm{~s}(\mathrm{~W})$ & $\begin{array}{l}\text { organics: } 0.3 \mu \mathrm{g} \mathrm{m}^{-3} \\
\text { nitrate: } 0.07 \mu \mathrm{g} \mathrm{m}^{-3} \\
\text { sulfate: } 0.06 \mu \mathrm{g} \mathrm{m}^{-3} \\
\text { ammonium: } 0.25 \mu \mathrm{g} \mathrm{m}^{-3}\end{array}$ \\
\hline MAAP $^{b}$ & Black carbon mass concentration & $10 \mathrm{~nm}-1 \mu \mathrm{m}$ & $1 \mathrm{~s}$ & $0.1 \mu \mathrm{g} \mathrm{m}^{-3}$ \\
\hline $\mathrm{CPC}^{\mathrm{c}}$ & Particle number concentration & $10 \mathrm{~nm}-3 \mu \mathrm{m}$ & $1 \mathrm{~s}$ & N/A \\
\hline FMPS $^{\mathrm{d}}$ (only summer) & Particle size distribution based on electrical mobility & $5.6 \mathrm{~nm}-560 \mathrm{~nm}$ ( 32 channels) & $1 \mathrm{~s}$ & N/A \\
\hline UHSAS $^{\mathrm{e}}$ (only winter) & Particle size distribution based on light scattering & $60 \mathrm{~nm}-1 \mu \mathrm{m}(100$ channels $)$ & $1-150 \mathrm{~s}$ & N/A \\
\hline $\mathrm{DC}^{\mathrm{f}}$ & Aerosol active surface area & $1 \mathrm{~nm}-1 \mu \mathrm{m}$ & $1 \mathrm{~s}$ & $10 \mu \mathrm{m}^{2} \mathrm{~cm}^{-3}$ \\
\hline Ozone-monitor $^{\mathrm{g}}$ & $\mathrm{O}_{3}$ mixing ratio & N/A & $2 \mathrm{~s}$ & $1 \mathrm{ppbV}$ \\
\hline $\mathrm{CO}$ analyser ${ }^{\mathrm{h}}$ & $\mathrm{CO}$ mixing ratio & N/A & $1 \mathrm{~s}$ & $2 \mathrm{ppbV}$ \\
\hline LI-7000 & $\mathrm{CO}_{2}$ and $\mathrm{H}_{2} \mathrm{O}$ mixing ratio & $\mathrm{N} / \mathrm{A}$ & $1 \mathrm{~s}$ & $\begin{array}{l}\mathrm{CO}_{2}: 0.035 \mathrm{ppmV} \text { (RMS noise) } \\
\mathrm{H}_{2} \mathrm{O}: 2 \mathrm{ppmV} \text { (RMS noise) }\end{array}$ \\
\hline $\mathrm{NO}_{\mathrm{x}}$ analyser $^{\mathrm{j}}$ & $\mathrm{NO}_{\mathrm{x}}$ mixing ratio & N/A & $1 \mathrm{~s}$ & $<100 \mathrm{pptV}$ \\
\hline Ambient temperature sensor ${ }^{\mathrm{k}}$ & Temperature & N/A & $<1 \min$ & Accuracy: $0.15^{\circ} \mathrm{C}$ \\
\hline Pressure sensor ${ }^{1}$ & Pressure & N/A & $<1 \min$ & Common standard \\
\hline HUMICAP sensor ${ }^{\mathrm{m}}$ & Relative humidity & N/A & $<1 \min$ & $\begin{array}{l}\text { Accuracy: } 2 \%(0-80 \% \mathrm{RH}) \\
3 \%(80-100 \% \mathrm{RH})\end{array}$ \\
\hline Wind sensor $^{\mathrm{n}}$ & Wind direction & N/A & $1 \mathrm{~s}$ & Common standard \\
\hline Pyranometer $^{\mathrm{O}}$ & Global radiation & N/A & $<1 \min$ & $\begin{array}{l}<1 \%\left(40^{\circ} / 60^{\circ} \text { zenith angle }\right) \\
<3 \%\left(80^{\circ} \text { zenith angle }\right)\end{array}$ \\
\hline GPSp & Vehicle location and speed & N/A & $2 \mathrm{~s}$ & N/A \\
\hline Webcam $^{\mathrm{q}}$ & Driver's view through windshield & N/A & $1 \mathrm{~s}$ & N/A \\
\hline
\end{tabular}

the two intercomparison periods show the same modes (nucleation mode around $20 \mathrm{~nm}$ particle diameter and accumulation mode around $100 \mathrm{~nm}$ ). The temporal trends of the size distribution are reproduced by both instruments. Smaller differences of the absolute concentration in some size channels mainly during the first intercomparison can be explained by an instrumental calibration error of the MOSQUITA instrument. During the second intercomparison this difference is no longer visible. In summer the FMPS size distribution measurements are consistent within the range of uncertainty of the devices.

During the winter campaign a different instrument for the particle size distribution measurement was applied in MOSQUITA. The UHSAS and FMPS devices overlap only in the size range between $55 \mathrm{~nm}$ and $560 \mathrm{~nm}$. In this size range temporal variations are represented by both instruments and the derived absolute number concentrations are in the same order of magnitude. The UHSAS can also be compared to OPC and APS in MoLa, because these instruments overlap in the size range from $0.25 \mu \mathrm{m}$ (OPC) and $0.5 \mu \mathrm{m}$ (APS) up to $1 \mu \mathrm{m}$. The density and shape of the measured particles is not exactly known, so the different equivalent diameters (FMPS: electrical mobility diameter, UHSAS: optical diameter, OPC: optical diameter, APS: aerodynamic diameter) were not converted into a common diameter for this intercomparison. The concentrations measured by the
UHSAS are on average between the concentration values measured by OPC and APS. Additionally, the three size distribution devices in MoLa were compared during both field campaigns. Here the average particle concentrations are in the same order of magnitude regarding the different equivalent particle diameters. In summary, with respect to the different measurement principles the agreement of all size distribution devices is sufficient for further combined analysis.

Particle number concentration: for the particle number concentration measurements we expect significant differences because the lower size cut-off of the CPCs is different. Figure 1a shows the time series of the particle number concentration recorded during the three intercomparison time periods by the CPCs in MoLa and MOSQUITA. While the MoLa-CPC has a lower cut-off of $2.5 \mathrm{~nm}$ the MOSQUITACPC detects particles larger than $10 \mathrm{~nm}$ and the MoLa instrument yields always similar or larger number concentrations as the other instrument. Accounting for the different size ranges the agreement of total number and temporal variations is satisfying and approximate comparability of the two measurements is given if no extreme concentrations of nucleation mode particles are present.

Non-refractory chemical particle components: for the intercomparison of measured non-refractory particle chemical components the time series of particulate organics, nitrate, sulfate, ammonium and chloride were studied. While for both 
HR-ToF-AMS data sets the same data processing routines were applied $(\mathrm{m} / \mathrm{z}$ calibration, baseline correction, instrument background measurements and additional calibration parameters) different values for the collection efficiency are used during the summer campaign. For the MoLa data set a standard collection efficiency of 0.5 (Matthew et al., 2008) is applied during both campaigns. For the MOSQUITA data set the same value was used in winter; however, a value of 1.0 was applied for the summer data set. This unusual collection efficiency is justified on the one hand by long-term experiences with the MOSQUITA instrument, reflecting instrumental features of this HR-ToF-AMS. On the other hand including all intercomparison measurements (not only AMS intercomparisons, but also AMS comparison with additional $\mathrm{PM}_{1}$ measurements) carried out during both campaigns it seems to be appropriate to apply different collection efficiencies for the MOSQUITA summer and winter AMS data. A second difference between the data sets is the mode of operation of the two HR-ToF-AMSs. The MoLa instrument switched between $10 \mathrm{~s}$ in the mass spectrum mode and $10 \mathrm{~s}$ in the particle time-of-flight mode, both in V-mode (medium resolution but high sensitivity) only. The MOSQUITA instrument applied shorter mode switching times, and also measured in V-mode only. During the summer campaign the AMS switched between $3 \mathrm{~s}$ in mass spectrum mode and $2 \mathrm{~s}$ in particle time-offlight mode. In winter it switched between $5 \mathrm{~s}$ in mass spectrum mode and $5 \mathrm{~s}$ in particle time-of-flight mode. Due to the shorter measurement time a higher temporal resolution (but also larger uncertainty) of the AMS data were achieved compared to the MoLa instrument.

In Table 3 the correlation parameters (slope and regression coefficient $R^{2}$ ) of linear fits of the MoLa versus MOSQUITA data for particulate organic, sulfate, nitrate and ammonium of the three intercomparison times are listed, as well as average ratios of mass concentrations of MoLa to MOSQUITA data and mean concentration values of both instruments. The given uncertainties represent the standard deviations of the respective parameters, which include ambient variations as well as instrumental noise. It can be seen that the MOSQUITA AMS measured always higher species mass concentrations than the MoLa instrument. During the summer campaign the average ratio of the MoLa to the MOSQUITA AMS concentrations is about 0.80 ; during the winter campaign this ratio seems to be lower with about 0.70 . The $R^{2}$ values are between 0.84 and 0.97 for the first intercomparison period, which implies that temporal variations are observed by both instruments similarly. The low $R^{2}$ values for nitrate and ammonium during the second intercomparison (summer) can be explained by low ambient concentrations of these components near or below the detection limit of the MOSQUITA AMS. In winter ambient concentrations were well above the detection limits of both instruments; however, especially for ammonium the $R^{2}$ value (0.39) is still low. Calibration errors of one or both instruments can be the reason for the observed differences
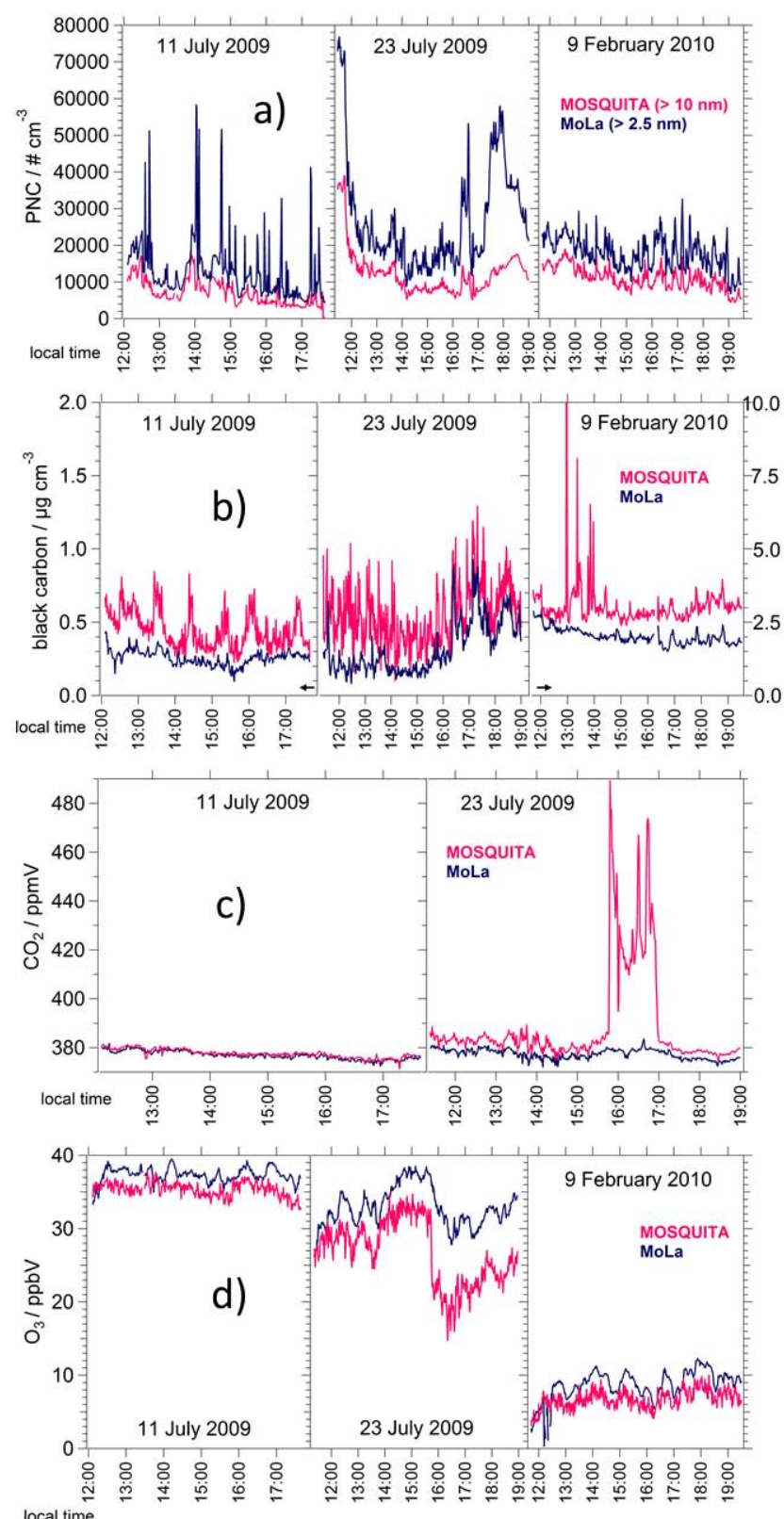

Fig. 1. Time series of the particle number concentration (PNC, panel a), black carbon concentration (panel b), $\mathrm{CO}_{2}$ mixing ratio (panel c) and $\mathrm{O}_{3}$ mixing ratio (panel d) recorded during the intercomparison time periods on 11 July 2009, 23 July 2009 and 9 February 2010 by the devices in MoLa (blue) and MOSQUITA (pink). $\mathrm{CO}_{2}$ data recorded by MOSQUITA are only available during the summer intercomparisons.

in absolute mass concentrations (indicated by the slope and the MoLa to MOSQUITA AMS averaged mass concentrations ratio) and discrepancies in the temporal behaviour of the AMS time series (indicated by $R^{2}$ ) could be explained by local emissions, which were detected only by one of the AMSs. Nevertheless, general temporal trends are represented 
similarly by both instruments during all three intercomparison periods.

The overall uncertainty of AMS data is, including all uncertainties of operation mode, instrumental differences, different inlet setups, calibrations and analysis variations, about $30 \%$ (Canagaratna et al., 2007), so the observed differences are within the range of uncertainty. Similar ranges of uncertainty were experienced during other intercomparison exercises as well (Bahreini et al., 2009). Intercomparisons of the MoLa and the MOSQUITA aerosol mass spectrometers with AMS instruments at the stationary measurement sites show similar discrepancies (Freutel et al., 2013; Crippa et al., 2013).

Black carbon mass concentration: Fig. 1b shows the time series of the black carbon concentration recorded during the three intercomparison time periods by the MAAP devices in MoLa and MOSQUITA. Although black carbon mass concentrations were measured with two identical instruments during the summer campaign the MOSQUITA device measured on average about $40 \%$ more than the MoLa device. In winter the difference was slightly lower at about $30 \%$. Long-term temporal variations were similarly represented by both instruments, but the concentrations measured by the MOSQUITA device seem to be much noisier. This significant difference in absolute concentrations can only be explained by calibration errors, deterioration of instrumental components and/or differences in the inlet systems. The MoLa MAAP sampled the aerosol through a $\mathrm{PM}_{1}$ cyclone (only particles up to $1 \mu \mathrm{m}$ were measured) while the MOSQUITA device was not operated in combination with a specific size selective aerosol inlet. Comparison results of the MoLa instrument with black carbon measurements at the stationary sites can be found in Freutel et al. (2013). In this publication the difference of identical MAAP instruments is satisfyingly small at about $10 \%$.

$\mathrm{CO}_{2}$ mixing ratio: Fig. 1c shows the time series of the $\mathrm{CO}_{2}$ mixing ratios recorded during the summer intercomparison time periods by the $\mathrm{CO}_{2}$ devices in MoLa and MOSQUITA. During the winter intercomparison the MOSQUITA device was not operational. During the first summer intercomparison (11 July 2009) both instruments show very good agreement of the recorded $\mathrm{CO}_{2}$ mixing ratios and the differences in absolute concentrations were below $1 \%$. The second summer intercomparison (23 July 2009) reveals larger differences of the recorded $\mathrm{CO}_{2}$ mixing rations. Between 16:00 and 17:00 local time the MOSQUITA instrument measured a strong $\mathrm{CO}_{2}$ concentration enhancement of about $50 \mathrm{ppmV}$. Since no external reason could be found for this (e.g. a strong local $\mathrm{CO}_{2}$ emission near the MOSQUITA inlet), an internal measurement device error is assumed.

$\mathrm{O}_{3}$ mixing ratio: Fig. 1d shows the time series of the $\mathrm{O}_{3}$ mixing ratios measured during the three intercomparison time periods by the $\mathrm{O}_{3}$ devices in MoLa and MOSQUITA. $\mathrm{O}_{3}$ mixing ratios also show comparable temporal variations. On average the MoLa instrument measured about $5 \%$ more than the MOSQUITA device during the first summer intercomparison and $25 \%$ more during the second one. In winter the difference is about $30 \%$. The MoLa instrument is less sensitive than the one in MOSQUITA and the difference could be explained by different instrument designs and calibration errors. Additional intercomparisons of both instruments to $\mathrm{O}_{3}$ devices at the fixed measurement sites show very good agreement for the MoLa instrument (summer and winter) and good comparability for the MOSQUITA device (only validated for summer, because in winter no additional intercomparison data are available).

$\mathrm{NO}_{\mathrm{x}}$ mixing ratio: due to calibration issues of the MOSQUITA instrument in summer an intercomparison can only be done for the winter data. Here the MOSQUITA instrument measured $30 \%$ less than the MoLa device. This discrepancy can be caused by calibration errors of one or both devices. The MoLa instrument applies a molybdenum converter for the $\mathrm{NO}_{\mathrm{x}}$ measurements, which causes additional uncertainty of the measured $\mathrm{NO}_{\mathrm{x}}$ mixing ratios (Steinbacher et al., 2007). Intercomparisons of the MoLa device with instruments at the fixed measurement sites show good results in summer and winter. No additional intercomparison data are available for the MOSQUITA device in winter.

In summary, the agreement of most parameters, except black carbon and $\mathrm{NO}_{\mathrm{x}}$, is within the range of uncertainty of the instruments and the data are sufficiently accurate for combined analysis. Aerosol sampling artifacts occurring in the two inlet systems and small scale (few metres) aerosol concentration differences should not have influenced the intercomparison in a significant way.

\subsection{Data preparation for analysis}

Mobile measurements can be adversely influenced by additional factors that are often negligible during stationary measurements. Especially local contamination caused by, for example, vehicles driving in front of the mobile laboratory or emission sources near the street is problematic for the processing of the measurement data. Pollution from these sources can dominate the measured data, since typically the concentrations of local emissions are large compared to ambient values. Those contaminations have to be removed from the data set when ambient air is supposed to be measured, e.g. when background and plume emissions are investigated. Separately analysed, the data points associated with local pollution contain valuable information about, for example, onroad pollutant emission indices or pollutant emission fluxes from point sources like industrial plants.

Another issue especially important for mobile measurements is the residence time of the aerosol in the inlet system. High temporal resolution (seconds) of the data is desired for analysis of mobile measurements and time shifts caused by transport of the aerosol should be corrected for. For both mobile laboratories the residence times for each instrument were calculated and verified by measurements. All mobile 
Table 3. Average ratios of MoLa data to MOSQUITA data, average concentration values in $\mu \mathrm{g} \mathrm{m}^{-3}$ of both HR-ToF-AMS instruments and two correlation parameters* (slope and regression coefficient $R^{2}$ ) for the three intercomparison time intervals for the measured variables submicron particulate organics, nitrate, sulfate and ammonium. Chloride data are not listed, because ambient values were below the detection limit most of the time. The given uncertainties represent one standard deviation.

\begin{tabular}{|c|c|c|c|c|}
\hline & organics & nitrate & sulfate & ammonium \\
\hline \multicolumn{5}{|c|}{11 July 2009 (334 min, middle aerosol load conditions) } \\
\hline MoLa/MOSQUITA & $0.81 \pm 0.05$ & $0.79 \pm 0.21$ & $0.74 \pm 0.05$ & $0.92 \pm 0.14$ \\
\hline Average MoLa & $2.24 \pm 0.29$ & $0.20 \pm 0.07$ & $1.15 \pm 0.11$ & $0.39 \pm 0.06$ \\
\hline Average MOSQUITA & $2.77 \pm 0.40$ & $0.27 \pm 0.13$ & $1.55 \pm 0.12$ & $0.43 \pm 0.07$ \\
\hline Slope & $1.24 \pm 0.01$ & $1.36 \pm 0.02$ & $1.34 \pm 0.01$ & $1.10 \pm 0.01$ \\
\hline$R^{2}$ & 0.97 & 0.97 & 0.76 & 0.84 \\
\hline \multicolumn{5}{|c|}{23 July 2009 (458 min, low aerosol load conditions) } \\
\hline MoLa/MOSQUITA & $0.83 \pm 0.08$ & $0.91 \pm 0.34$ & $0.69 \pm 0.05$ & $0.89 \pm 0.22$ \\
\hline Average MoLa & $1.09 \pm 0.23$ & $0.07 \pm 0.02$ & $0.45 \pm 0.05$ & $0.16 \pm 0.03$ \\
\hline Average MOSQUITA & $1.30 \pm 0.18$ & $0.08 \pm 0.03$ & $0.66 \pm 0.07$ & $0.19 \pm 0.04$ \\
\hline Slope & $1.19 \pm 0.02$ & $1.20 \pm 0.04$ & $1.46 \pm 0.02$ & $1.14 \pm 0.03$ \\
\hline$R^{2}$ & 0.68 & 0.61 & 0.82 & 0.38 \\
\hline \multicolumn{5}{|c|}{9 February 2010 (468 min, high aerosol load conditions) } \\
\hline MoLa/MOSQUITA & $0.70 \pm 0.07$ & $0.69 \pm 0.08$ & $0.80 \pm 0.09$ & $0.63 \pm 0.06$ \\
\hline Average MoLa & $7.64 \pm 2.68$ & $6.79 \pm 1.08$ & $8.14 \pm 1.13$ & $4.21 \pm 0.42$ \\
\hline Average MOSQUITA & $10.97 \pm 3.38$ & $10.14 \pm 1.03$ & $10.46 \pm 2.12$ & $6.78 \pm 0.87$ \\
\hline Slope & $1.43 \pm 0.02$ & $1.43 \pm 0.03$ & $1.29 \pm 0.02$ & $1.60 \pm 0.03$ \\
\hline$R^{2}$ & 0.88 & 0.53 & 0.84 & 0.39 \\
\hline
\end{tabular}

* Linear fit through zero for MOSQUITA AMS data versus MoLa AMS data (15 min averages of organics, nitrate, sulfate and ammonium, respectively).

measurement data were corrected for the residence time in the inlet system. Due to the optimisation and characterisation of both inlet systems particle losses during transport to the instruments are known and of a negligible order of magnitude. For more details see Bukowiecki et al. (2002), Mohr et al. (2011) and Drewnick et al. (2012).

To obtain as much information as possible especially from HR-ToF-AMS data several advanced analysis methods are available. Two of them, PMF and PIKA were used for the processing of this data set and are introduced in Sects. 2.3.2 and 2.3.3.

\subsubsection{Removal of local contamination}

Several methods, like automatic concentration peak removal, were tested to obtain uncontaminated mobile data sets that are not influenced by local pollution emissions and the "video tape analysis procedure" finally was selected. More details on different local pollution removal strategies and examples of "before - after" time series are presented in Drewnick et al. (2012).

Video tape analysis procedure: during the analysis of the MEGAPOLI data set it has become apparent that the most consistent method to identify local contamination is to analyse the video tapes of mobile measurements recorded by the webcam in the driver's cabin. Therefore several criteria for contaminated time periods were defined:
- Times whilst driving through a village/town due to higher traffic, heating, cooking and other human activities.

- Times when a vehicle is less than about $150 \mathrm{~m}$ in front of the mobile laboratory or when there is significant traffic on the road including the opposite lane.

- Times while the driving velocity of the mobile laboratory is low increasing the possibility of contamination by the own exhaust.

- Times while next to the street a source of local contamination is visible, for example a burning fire or a working tractor.

- Times while driving through a tunnel, because exhaust emissions might be accumulated.

All $1 \mathrm{~s}$ intervals fulfilling at least one of these criteria are marked as contaminated and corresponding data points are removed before further analysis. For data with lower time resolution, minutes with more than 20 contaminated $1 \mathrm{~s}$ intervals are also removed. This criterion is somewhat arbitrary, but seems to be a good balance between removing partly contaminated data and keeping as much data as possible. This method treats all instrument time series equally and it delivers the most objective uncontaminated data due to the direct pollution source identification. Unfortunately, it is a very 
time consuming method (approximately $30 \mathrm{~min}$ of analysis time for $60 \mathrm{~min}$ of measurement time). Meanwhile, there has been some effort made to automate the local pollution detection. During mobile MoLa measurements, it is now possible to note via a mouse click the time period and the kind of pollution event occurring. With this information a contamination mask is created, which can be used to analyse the data.

Only for a first interpretation of the individual measurement trips the contaminated data sets can be used to avoid the time-consuming pollution removal procedure for data sets that are not used for later analysis. For all further analysis of the Paris emission plume only the uncontaminated data were used to obtain best results and conclusions.

\subsubsection{Positive matrix factorization}

Positive matrix factorization (PMF) is used to identify aerosol types in the atmosphere that can be associated with different sources. The underlying statistical procedure is based on the principle of mass conservation. Such methods, which use measured ambient concentrations as inputs and estimate source contributions, are generally known as receptor models. They are used to reduce large data sets by estimation of number of potential aerosol sources and composition of aerosols related to them ("factors" that explain the data variability). Part of this study is to identify different sources of organic aerosol contributing to the emission plume from the Paris agglomeration. The importance of organic aerosol is demonstrated by its high fraction of the total submicron aerosol mass. It can consist of multiple organic components and the scientific interest in formation and transformation processes in the atmosphere is high (Jimenez et al., 2009; Lanz et al., 2010). Therefore, PMF became one of the standard analysis techniques for HR-ToF-AMS data in the past few years (Zhang et al., 2011). With this method it is possible to extract factors representing not only organic aerosol of different sources but also organic aerosol of different oxidation states which is correlated to the age of the aerosol. However, the mathematical algorithm of PMF has several uncertainties by itself (e.g. start value "seed" of the calculation and rotational freedom of the solution given by the parameter "fpeak") and the freedom of the user inputs and interpretation adds additional uncertainty. Comparison of PMF results with external time series of other instruments and with mass spectra from known sources are tools for embedding those results in a greater context to identify the potential chemical nature of a certain PMF factor. For more details about the underlying mathematical algorithm and the applied software, we refer to Paatero and Tapper (1994), Paatero (1997), Lanz et al. (2007) and Ulbrich et al. (2009).

PMF of MEGAPOLI mobile data sets: PMF was applied to both mobile unit mass resolution AMS data sets including all data sampled during the respective measurement campaigns. For the MoLa summer data set the organic aerosol can be described by five factors (hydrocarbon-like organic aerosol (HOA), low-volatile oxygenated organic aerosol (LVOOA), cooking-related organic aerosol (COA) and two types of oxygenated organic aerosol with higher volatility). In winter the 6 factor solution (HOA, LV-OOA, COA, two types of organic aerosol associated with biomass burning and one factor with higher volatility) provides a good approximation of the composition of the particulate organic matter. PMF for the MOSQUITA mobile data sets resulted in mainly two factors for the summer (HOA and LV-OOA) and an additional third factor for the winter campaign which is also associated with biomass burning. HOA and LV-OOA are especially interesting for the identification of the Paris emission plume. HOA is mainly associated with fresh emissions (Zhang et al., 2005), e.g. from traffic like in the emission plume air masses, while LV-OOA mainly represents highly oxidized long-range transported air masses which characterise the ambient background atmosphere. In Sect. 3.3 an example of the MoLa PMF results is presented. For further description of the mentioned factors (HOA, LV-OOA, etc.), we refer to Zhang et al. (2011). Details about the extracted factors and their identification using correlations with external time series and mass spectra, quantified uncertainties and interpretation of the scientific content of the PMF results would exceed the scope of this overview paper. There will be further publications based on these mobile data sets including a detailed PMF discussion (e.g. von der Weiden-Reinmüller et al., 2013).

\subsubsection{Peak integration by key analysis}

PIKA (Peak Integration by Key Analysis; ToF-AMS Analysis Software Homepage, 2013) is another advanced analysis software tool for the speciation and quantification of HRToF-AMS data. PIKA is based on SQUIRREL (SeQUential Igor data RetRiEvaL; ToF-AMS Analysis Software Homepage, 2013), the standard software for basic analysis of AMS data, e.g. for application of calibration parameters and to obtain chemically resolved mass concentration time series or particle size distributions. In newer versions PIKA includes APES (Analytical Procedure for Elemental Separation; ToFAMS Analysis Software Homepage, 2013), a software tool for the separation of high resolution AMS signals into their elemental components. In this study PIKA was mainly applied for the retrieval of the $\mathrm{O} / \mathrm{C}$ ratio of the organic aerosol which is a marker for the oxidation state and therewith the age of the aerosol. In Sect. 3.2 an example of aerosol with low $\mathrm{O} / \mathrm{C}$ ratio as marker for fresh emissions in the Paris plume is presented. More details about PIKA, SQUIRREL and APES can be found on the developers' website (ToFAMS Analysis Software Homepage, 2013).

\subsection{Measurement strategies}

Depending on environmental conditions like predicted plume strength, intensity and direction different measurement strategies were applied. For the decision which type of 


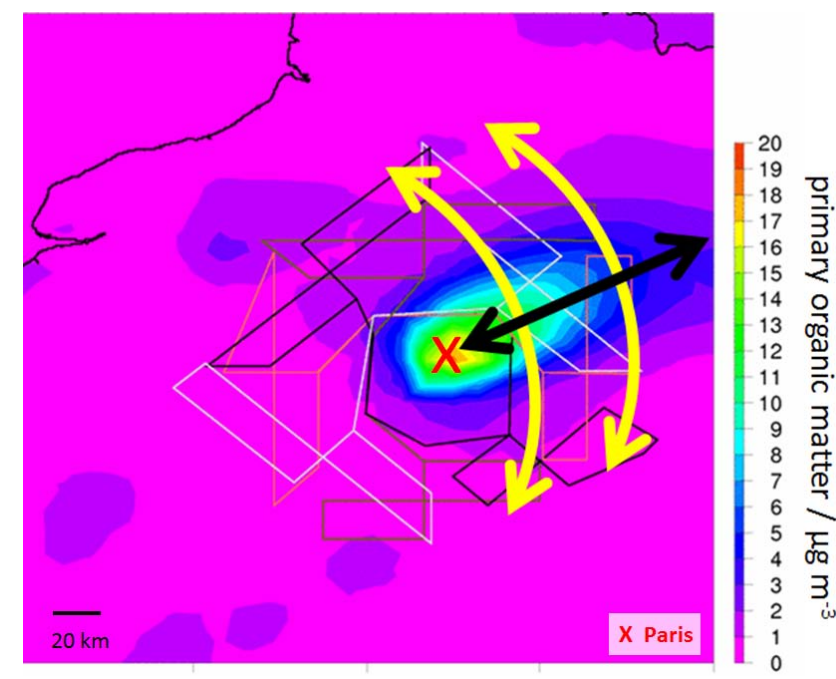

Fig. 2. Prev' Air Paris emission plume actual day forecast for 31 January 2010 18:00:00 UTC during the winter field campaign. The colour code indicates the concentration of primary organic matter, a marker for fresh air pollution. Paris is located in the middle of the straight black and grey lines (concentration colour code: yellow/orange, red X), which indicate potential flight routes for the research aircraft. The yellow arrows demonstrate cross-section measurements of several ten to hundred kilometres at two different distances to Paris. The black arrow indicates axial measurements starting at the outer areas of Paris up to about $200 \mathrm{~km}$ away from the city.

measurement is most useful for a specific day regional plume prediction maps for pollutant markers like primary organic matter were provided by Prev'Air (Honoré et al., 2008).

Prev'Air plume prediction maps: the Prev'Air forecast system (Prev'Air, 2013) started in 2003 and is based on global, European and national forecast simulations. The aim is to provide daily air quality forecast and re-analysis maps of pollutant markers like $\mathrm{O}_{3}, \mathrm{NO}_{2}, \mathrm{PM}_{10}$ and $\mathrm{PM}_{2.5}$ for $\mathrm{Eu}$ rope and France. Air quality maps are provided as 2-day (e.g. simulating on Monday the air quality situation occurring on Wednesday), 1-day and actual day forecasts and as retrospective re-analysis. These re-analysis maps - a combination of a posteriori simulations and observations - are the most objective representation of the pollution situation. They were also used for our mobile measurements analysis (e.g. to check which part of the measurement route was located within the Paris emission plume). For the campaign planning specific forecasts were made available by INERIS (Institut National de l'Environnement Industriel et des Risques, Verneuil en Halatte, France), running the Prev'Air system with an enhanced forecast frequency $(3 \mathrm{~h})$ and additional compounds (e.g. primary and secondary organic matter, see Fig. 2).

Measurement planning: for the measurement planning 1day forecast maps were applied for a rough route planning on the evening before the measurement day. A combination of high resolution printed fold-up maps and actual day forecast maps was used in the morning of the measurement day to decide on the actual driving route. Ideal routes for the investigation of a megacity emission plume avoid forests, streets with heavy traffic, larger villages and towns and regions with strong local pollution like proximate industrial plants. In general, mobile measurements were carried out on minor roads with less traffic to avoid local pollution sources as much as possible. Stationary measurement sites were chosen applying similar considerations. Additional attention was paid to provide a free undisturbed flow of the air masses to the sampling location. So, places behind trees or in valleys were avoided as well as places downwind of local pollution sources like villages or major streets.

In summary, MoLa performed a total of 31 mobile (including 6 axial trips) and 25 stationary measurements of several hours measurement time each during both campaigns. MOSQUITA measured 17 times on the road, including one mobile measurement late in the evening. Stationary measurements were performed with MOSQUITA only for intercomparison purposes.

\subsubsection{Cross-section measurements}

To distinguish between ambient background and emission plume influenced aerosol and trace gas loadings of the ground-level atmosphere cross-section measurements are beneficial. A cross-section measurement usually starts in a region not influenced by the emission plume, then crosses the plume at a nearly constant distance to the city and ends again in background air masses. Several cross-section measurements at different distances from the city provide additional information about dilution and aging processes in the plume during transport. Applying this type of measurement, it is also possible to investigate the cross-sectional structure of the plume and dilution processes at the plume border. If the predicted emission plume was distinct and reasonably stable in direction over a sufficient number of hours (to finish a significant fraction of the measurement during this time), cross-section measurements were carried out. Problems with this type of measurement occur when the plume is changing its direction during the day. To cover the plume as well as background air masses usually takes several hours. So a shifting plume can appear deformed in the measured data with a broader, narrower or more heterogeneous shape than it was in reality.

In Fig. 2 an example of the emission plume forecast maps is shown for 31 January 2010. The concentrations of the presented primary organic matter in the aerosol are represented by the colour code. The yellow arrows demonstrate cross-section measurements at several distances from Paris. In Sect. 3.2 a measurement example of four cross sections performed during the summer campaign by MoLa and MOSQUITA is presented. 


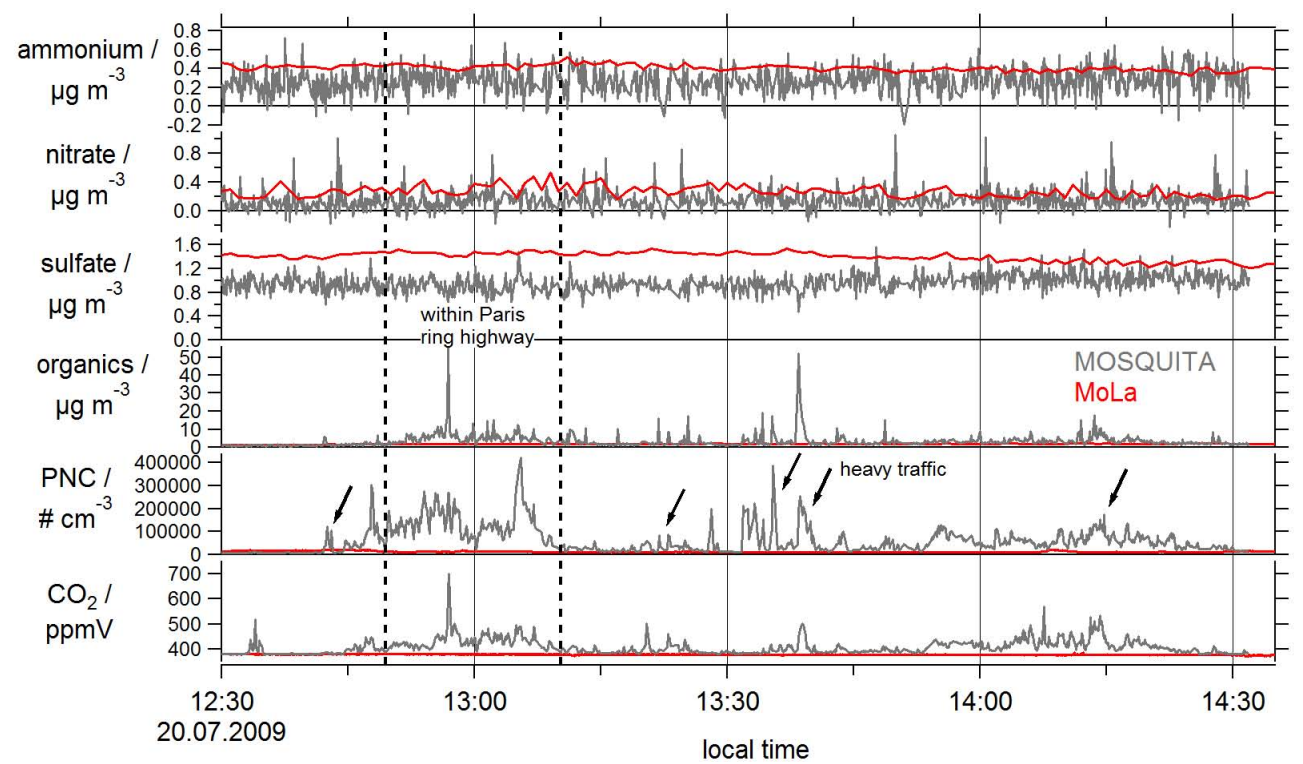

Fig. 3. Temporal behaviour of aerosol parameters primarily associated with long-range transported pollution (ammonium, nitrate and sulfate) and variables reflecting mainly locally and regionally produced pollution (organics, particle number concentration (PNC, $>2.5 \mathrm{~nm}$ for MoLa and $>10 \mathrm{~nm}$ for MOSQUITA) and $\mathrm{CO}_{2}$ ). The red lines represent the MoLa stationary measurement data and the grey lines the MOSQUITA mobile measurement data. The two vertical dashed lines frame the mobile measurement range within the city area of Paris; the arrows indicate measurement times with heavy traffic on the street. The time series were measured by MOSQUITA (outward trip) and MoLa during the summer campaign on 20 July 2009. The time resolution of the data is $1-7$ s (MOSQUITA) and 1-60 s (MoLa). The stationary measurement location of MoLa and the mobile measurement track (outward trip) of MOSQUITA are marked in the map of Fig. 4.

\subsubsection{Axial measurements}

To get insight into the spatial extent of the plume, i.e. up to which distance from the city it can be observed as significantly above background level, axial measurements are beneficial. The quasi-Lagrangian character (following an individual air parcel along its trajectory) of such measurements also allows investigating atmospheric conversion processes, like oxidation of organic aerosol or ozone build-up from precursor gases, during transport and dilution with increasing distance to Paris. In Fig. 2 the black arrow represents axial measurements starting at the outer suburbs of Paris and reaching as far as about $200 \mathrm{~km}$ away from the city. For this type of measurement a distinct emission plume with constant wind conditions is necessary. A wind shift of a few degrees over several hours is tolerable and the axial measurement route still should be located inside the plume. The megacity Paris is an area source of pollution and therefore the emission plume can be expected to have a width of more than ten kilometres. Appropriate weather conditions were identified only during three days during both campaigns. An additional issue with this type of measurement appears when major roads or larger towns are located in the predicted plume direction. Fresh pollution from these local sources will mix with the Paris emission plume and change its physical and chemical properties like average oxidation state of the organic aerosol or number concentration of small particles.
MoLa carried out three axial trips up to $180 \mathrm{~km}$ away from the city border during the summer campaign. In winter three axial trips up to $100 \mathrm{~km}$ distance from Paris were performed. MOSQUITA performed most of the mobile measurements as a combination of cross sections and axial trips to cover a wide area. With this strategy it is easier to measure the emission plume even if the plume direction is slightly uncertain or changing. The disadvantage of this method is that the distance to Paris that can be covered within several hours is not as large as on a straight axial trip. In Sect. 3.3 a measurement example of an axial trip performed during the summer campaign by MoLa is presented.

\subsubsection{Stationary measurements}

This type of measurement was often chosen when plume predictions were not sufficiently stable for mobile measurements. Measurement sites downwind of Paris allow measuring the emission plume for several hours at a certain distance and locations upwind of Paris were used for ambient background measurements.

Some stationary measurements were carried out in background air masses far away from the city without any impact by emissions from Paris. These measurements contain valuable information about real background concentrations for comparison with the fixed measurement sites that were influenced by local and regional emissions most of the time 


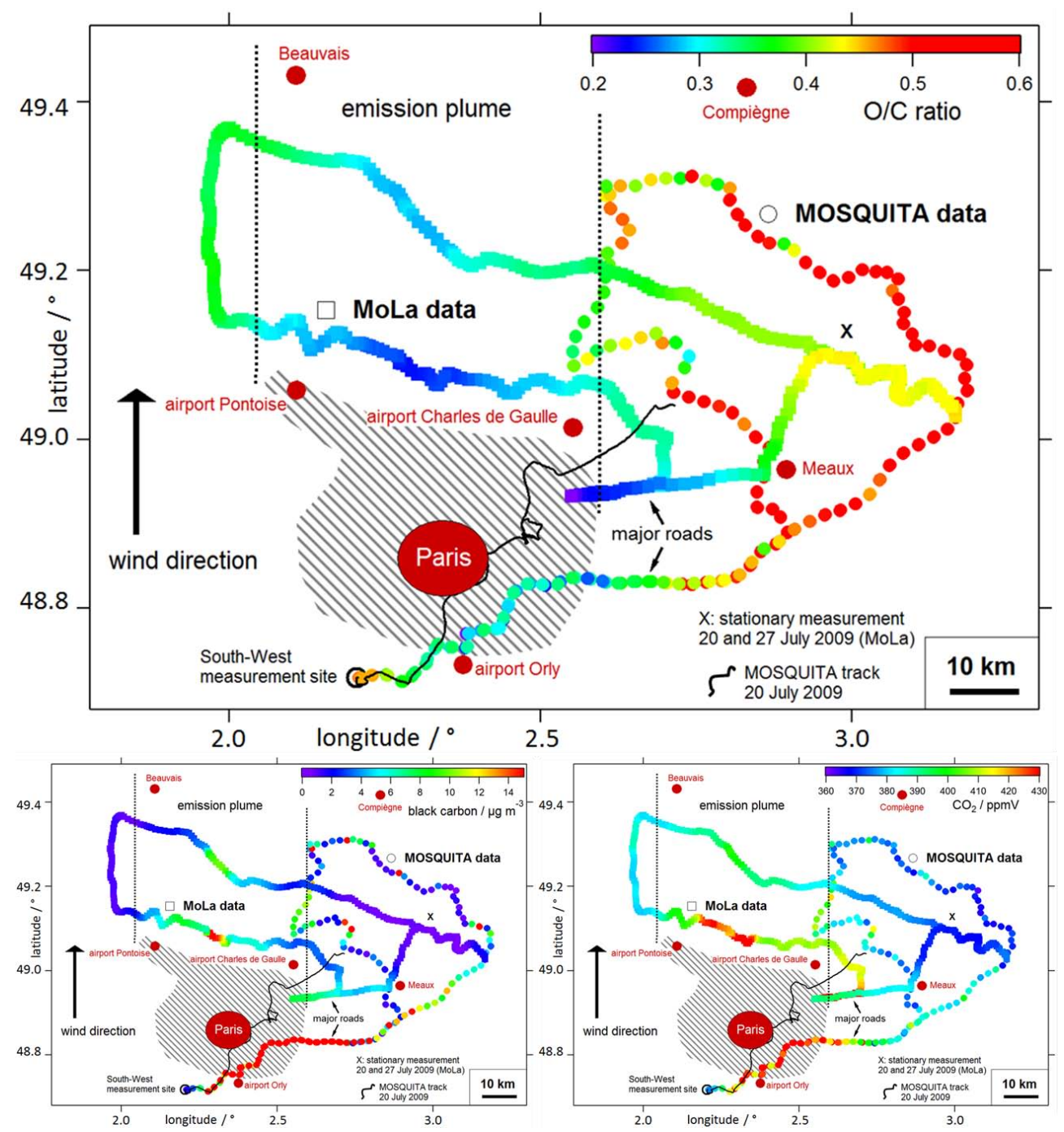

Fig. 4. Combined results of MoLa (line of squares) and MOSQUITA (dotted line) mobile applications of four cross-section measurements through the Paris emission plume during the summer campaign on 29 July 2009. Both data sets have a time resolution of 1 min, but were smoothed for this graph (boxcar smoothing algorithm, 10 points). The regional wind direction was constantly from South on this day (black arrow). The track is colour-coded by the $\mathrm{O} / \mathrm{C}$ ratio (upper large graph), black carbon mass concentration (lower left graph) and $\mathrm{CO}_{2}$ mixing ratio (lower right graph). The urban area of Paris is marked by the big red dot, the Paris metropolitan area is indicated by the grey shaded area. The cross ("X") marks the location of the stationary measurements on 20 and 27 July 2009 (see Sects. 3.1 and 3.4). The black thin line shows the track of the MOSQUITA mobile measurement on 20 July 2009 (see Sect. 3.1).

(Beekmann et al., 2014; Freutel et al., 2013). A few measurements show both, the Paris emission plume and the atmospheric background values when the wind direction was shifting. For these data sets the investigation of plume structure and homogeneity is possible. An example of such a measurement is presented in Sect. 3.4. For measurements located in the direction of the predicted plume and in line with stationary measurement sites (connected flow between all measurement locations) investigation of conversion and dilution processes during transport is also possible. This approach was adopted by Freutel et al. (2013) for the MEGAPOLI campaigns.

\section{Examples for the different measurement strategies}

In this section four measurement examples are presented to demonstrate the successful application of the developed measurement strategies and analysis methods for the investigation of the Paris emission plume.

\subsection{Long-range transport of pollution versus local and regional pollution}

Measurement example: on 20 July 2009 the mobile laboratory MOSQUITA performed an axial trip up to $15 \mathrm{~km}$ from the border of the Paris metropolitan area in the North-East 
direction of Paris. This mobile measurement (for the track see Fig. 4) included passes through the city centre of Paris (a large and inhomogeneous source of fresh pollution) on the outward and return journey from the starting point (fixed suburb measurement site in the South-West of Paris). At the same time MoLa performed a stationary measurement at about $30 \mathrm{~km}$ distance to the border of the metropolitan area also in the North-East of Paris (for measurement location also see Fig. 4). The Paris emission plume was advected to the North-East direction, so both mobile laboratories should have encountered air masses influenced by Paris.

In Fig. 3 time series of six aerosol and gas phase variables measured by MOSQUITA during the outward trip can be seen. Additionally, the same measurement variables recorded by the stationary MoLa are shown. Three time series represent aerosol species that are associated with long-range transported pollution (ammonium, nitrate, sulfate) and the other three are dominated by local and regional pollution (organics, particle number concentration, $\mathrm{CO}_{2}$ ). For better illustration of the different temporal and spatial behaviour of fresh and aged pollution markers no local pollution removal procedure (as described in Sect. 2.3.1) was applied to the presented data.

The time series of particulate organic matter shows signatures of both pollution types. The measured organics are a mixture of long-range transported highly oxidized (aged) organic aerosol, semi-volatile medium-aged organic aerosol, primarily produced hydrocarbon-like organic aerosol (mainly associated with traffic emissions) and freshly produced organic aerosol caused by various emission sources (e.g. cooking, biomass burning). In Fig. 3 the fresh and local fractions of the organic aerosol can be clearly identified by the various concentration peaks. The long-range transported part of the organic aerosol is represented by an underlying slowly varying concentration level of about 1 to $2 \mu \mathrm{g} \mathrm{m}^{-3}$, also measured by the stationary MoLa.

The time series of the particle number concentration (> $10 \mathrm{~nm}$ for MOSQUITA) is also dominated by frequent concentration changes due to the various sources probed during the drive. The long-range transported fraction (accumulated and grown particles with a mode diameter larger than $100 \mathrm{~nm}$ ) of the particle number concentration is small compared to the large number of freshly emitted small particles with a few nanometers particle diameter.

Concerning $\mathrm{CO}_{2}$, Fig. 3 shows mainly the peak concentrations from fresh pollution, due to the axis scaling. After several hours of transportation the fresh $\mathrm{CO}_{2}$ contributions are totally diluted in the surrounding air masses, but momentary $\mathrm{CO}_{2}$ concentrations measured near the source can reach about twice the global background concentrations which can be seen in the presented time series measured by MOSQUITA. $\mathrm{CO}_{2}$ mixing ratios measured by MoLa show nearly constant values around $378 \mathrm{ppmV}( \pm 2 \mathrm{ppmV})$, because no nearby local emission sources influenced the measurement location. A similar temporal behaviour can be seen for particle number and organic aerosol mass concentrations during this MoLa stationary measurement.

In contrast to the behaviour of the pollutants related to fresh emissions the time series of particulate ammonium, nitrate and sulfate measured with both mobile laboratories show only small and slow variations in time despite rapid fluctuations around the actual background value, mainly caused by instrumental noise (especially for ammonium, where the measured values are close to the detection limit of this species for the MOSQUITA AMS). This is a typical behaviour for substances that change only on large temporal and spatial scales under the influence of different air masses. Of course, in reality there are not only the two extremes of very local fresh pollution plumes and completely homogeneously distributed long-range transported air masses. There are also air masses where secondary aerosol is inhomogeneously mixed because the precursor substances have been emitted inhomogeneously.

\subsection{Cross section through the Paris emission plume: combination of MoLa and MOSQUITA data}

Measurement example: on 29 July 2009 the Paris emission plume was constantly advected towards the North. Both mobile laboratories carried out two cross-section measurements each in the North and North-East region around Paris. MoLa performed two cross sections at $10 \mathrm{~km}$ and $30 \mathrm{~km}$ distance from the Paris metropolitan area and MOSQUITA two crosssectional transects at $20 \mathrm{~km}$ and $40 \mathrm{~km}$ distance. In Fig. 4 the measurement tracks of both mobile laboratories colourcoded with the $\mathrm{O} / \mathrm{C}$ ratio, the black carbon mass concentration and the $\mathrm{CO}_{2}$ mixing ratio are presented on a map of the region. Low $\mathrm{O} / \mathrm{C}$ ratios indicate less oxidized fresh organic aerosol, high $\mathrm{O} / \mathrm{C}$ ratios indicate highly oxidized aged organic aerosol (Aiken et al., 2007, 2008). The low O/C ratio values $(<0.2)$ in the South and East of Paris are caused by heavy traffic on major roads and thus local contamination. The interesting result of this measurement is the low values measured in the North of Paris - carried out on minor roads with less traffic - which are clearly associated with the Paris emission plume. At the same distance to the city but in the North-East direction much higher $\mathrm{O} / \mathrm{C}$ ratios $(>0.6)$ were observed indicating aged background air masses not influenced by the city. Simultaneously with low $\mathrm{O} / \mathrm{C}$ values increased black carbon and $\mathrm{CO}_{2}$ concentrations were observed, confirming the identification of the emission plume in the North of Paris.

The same map but with the measured tracks of markers for aged pollution in long-range transported air masses like particulate ammonium shows different spatial distribution of these substances. There is no enhancement in concentrations in emission plume influenced regions. Higher values are also detected in the most Eastern part of the cross sections, where the highest $\mathrm{O} / \mathrm{C}$ ratios were seen. This is a further indication that in this region primarily an aged air mass containing 
long-range transported pollution was probed on this day. This detailed picture of plume and background air masses in a wide area around Paris can be obtained due to the combination of the data from both mobile laboratories.

The emission plume as visible in the $\mathrm{O} / \mathrm{C}$ ratios (and also black carbon and $\mathrm{CO}_{2}$ concentrations) in Fig. 4 looks rather homogeneous with a definite structure (i.e. the lowest $\mathrm{O} / \mathrm{C}$ ratios in the centre of the plume, with gradually increasing ratios to both sides) even in the nearest cross section performed by MoLa only $20 \mathrm{~km}$ away from the border of Paris. Within this distance one could expect a more inhomogeneous structure due to the short transportation time of about $1 \mathrm{~h} \mathrm{(av-}$ eraged wind speed about $20 \mathrm{~km} \mathrm{~h}^{-1}$ on this day) from this large diversified emission source. For more details on this and about the plume structure analysis we refer to the future publication by von der Weiden-Reinmüller et al. (2013).

\subsection{Axial measurement: exploring the spatial extent of the emission plume}

Measurement example: on 1 July 2009 weather conditions and the predicted plume were sufficiently stable and welldefined for an axial measurement. The North-Eastern wind advected the Paris emission plume to the South-West, where MoLa performed an axial trip up to $160 \mathrm{~km}$ from Paris centre. On this day only MoLa was deployed. Figure 5 presents black carbon, $\mathrm{HOA}$ and sulfate mass concentrations and $\mathrm{O}_{3}$ mixing ratios versus the distance to the centre of Paris. In the upper part of the graph results from the outward trip carried out during the morning can be seen, in the lower part results from the return trip during the afternoon are shown. Although the contamination removal was applied to the data, still few locally influenced high concentration values can be seen.

Nevertheless, a clear decrease of black carbon and HOA concentrations in the emission plume can be observed with increasing distance to Paris. On the outward trip the emission plume that is observable with our measurements extends approximately up to $30 \mathrm{~km}$ distance from the outer areas of Paris which is equal to $50 \mathrm{~km}$ distance to Paris centre. During the day the emission plume seems to develop and intensify. On the return trip the range of the detected plume increased to a distance of about 80 to $100 \mathrm{~km}$ from Paris centre. The decrease in concentration with increasing distance from the city is mainly caused by dilution of the emission plume in surrounding background air masses. The wind direction was nearly constant during the measurement, so we assume that we measured constantly in the lateral plume core and the decrease in fresh pollutants should not be caused by leaving the plume. We expect within this time frame of several hours no significant black carbon sinks like dry deposition and there was no precipitation causing wet deposition on this day. Moreover, HOA is not transformed into secondary organic aerosol within this time frame. In regions near the city black carbon concentrations are approximately ten times higher ( 7 to $\left.10 \mu \mathrm{g} \mathrm{m}^{-3}\right)$ than in background air masses $(0.5$ to $1 \mu \mathrm{g} \mathrm{m}^{-3}$ ). HOA concentrations vary from $1.5 \mu \mathrm{g} \mathrm{m}^{-3}$ near the city to around $0.5 \mu \mathrm{g} \mathrm{m}^{-3}$ in background air masses.

During the return trip at a distance of about $110 \mathrm{~km}$ to Paris centre concentration peaks of black carbon $\left(>6 \mu \mathrm{g} \mathrm{m}^{-3}\right)$ were measured, although local contamination was removed by video analysis. In this region two larger villages with a commercial area are located resulting in a regionally higher traffic volume and therefore causing a regional pollution hot spot. Here the limits of the applied local pollution removal procedure become obvious, because only "visible" (in the video tapes) contamination sources in front of the vehicle can be identified. Measurements on a near bypass road (where no local pollution source is recorded by the webcam) can still be affected by locally distributed emissions. Nevertheless, the spatial extent of the Paris emissions plume can be clearly seen and also quantified in the presented data. The described decreasing concentrations with increasing distance from Paris were not only observed in black carbon and HOA mass concentrations, but also in related fresh pollution markers like PAH and $\mathrm{CO}_{2}$ (not shown in Fig. 5).

Additionally, we calculated the average HOA to $\mathrm{BC}$ ratio for plume and background air masses for both axial trips. If both substances are only diluted in the advected emission plume and no conversion processes occur, this ratio should not change with increasing distance to Paris. For both trips the HOA to $\mathrm{BC}$ ratio is on average about 0.3 inside the plume, while in background air masses the ratio is higher: 0.4 for the outward trip and 0.6 for the return trip. This could be explained by higher HOA than BC background levels compared to the respective pollutant burden in the emission plume. Possibly, HOA emitters are more frequently distributed also in rural areas than $\mathrm{BC}$ emitters. It was not possible to identify transformation processes due to the HOA to $\mathrm{BC}$ ratio with increasing distance to Paris and results on transformation processes in the advected emission plume will be discussed in a separate publication (von der Weiden-Reinmüller et al., 2013).

$\mathrm{O}_{3}$ mixing ratios are decreased by about $30 \mathrm{ppbV}$ near the city and reach a nearly constant background value of about $80 \mathrm{ppbV}$ at a distance of approximately $30 \mathrm{~km}$ from the city border. The ozone depletion near the city is caused by increased NO concentrations from fresh emissions in the city. During the outward trip (before noon) the atmospheric conditions seem to have not been suitable for significant ozone production downwind of Paris. In contrast to this, on the return trip (in the afternoon) we observe ozone production from precursor gases emitted in Paris at a distance of about $30 \mathrm{~km}$ away from the city border. Here the $\mathrm{O}_{3}$ mixing ratios peak around $110 \mathrm{ppbV}$. Lower $\mathrm{O}_{3}$ concentrations are also observed near the city (around $10 \mathrm{~km}$ from the city border); background $\mathrm{O}_{3}$ levels of 70 to $80 \mathrm{ppbV}$ are reached at a distance of about $80 \mathrm{~km}$ from the city border. The intensified solar radiation in the afternoon is probably the reason for the significant ozone production observed during the return trip. 


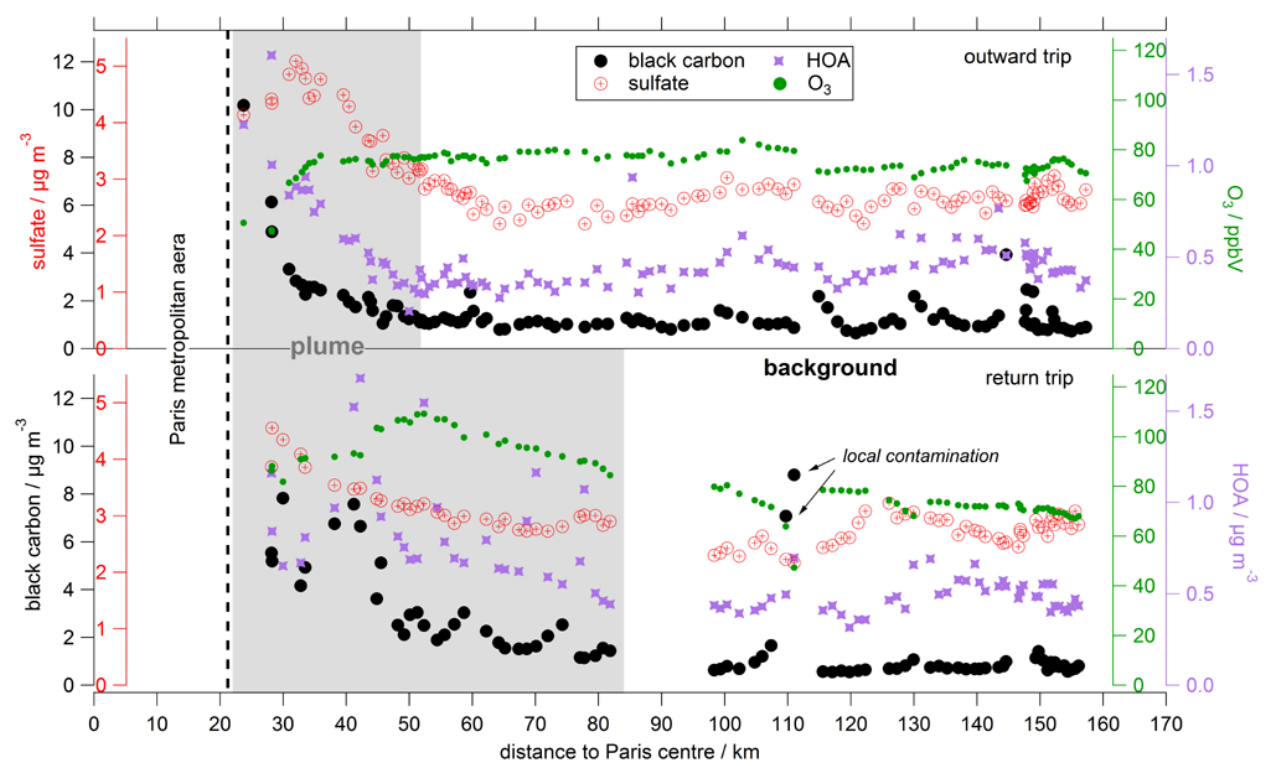

Fig. 5. Black carbon (large black dots), $\mathrm{HOA}$ (purple stars) and sulfate (red dots and crosses) mass concentrations and $\mathrm{O}_{3}$ mixing ratio (small green dots) versus distance to Paris centre measured during an axial trip on 1 July 2009 by the mobile laboratory MoLa. In the upper part of this graph results of the outward trip carried out during the morning are presented, in the lower part results from the return trip during the afternoon. The data points identified as significantly influenced by the Paris emission plume are indicated by the grey area. The time resolution of the data is $1 \mathrm{~min}$.

Surprisingly, during this axial trip also long-range transported secondary pollution markers like sulfate (see Fig. 5) and nitrate show a decrease in concentration (a factor of two to three for sulfate and a factor of four to ten for nitrate) with increasing distance to Paris. It is possible that long-range transported pollution was mixed with the probed megacity emissions. At the downtown and suburb South-West measurement sites an increase in sulfate was observed during the morning of 1 July 2009, followed by decreasing concentrations in the afternoon and enhanced values again in the evening. In contrast to this, fresh pollutant markers showed a different temporal behaviour on this day. However, during other axial trips like the one performed with MoLa on 25 July 2009 increased concentrations of sulfate are not measured near Paris but at a distance of about $100 \mathrm{~km}$. These are both indicators that we measured the Paris emission plume with some mixed-in long-range transported pollution.

Another explanation for the observed decrease in concentration of most of the measured pollutants with increasing distance to Paris could be that the few axial trips carried out had been performed mainly during the same time of day (starting in the morning in Paris and returning in the evening). Usually, the atmospheric boundary layer develops during the day and breaks down in the evening. High measured concentrations could therefore also be correlated to a low boundary layer height, accidentally associated with measurements near the city. However, the measured data of the axial trip on 25 July 2009 show a contrary trend for some of the measured variables: no enhancement of ammonium and sulfate could be observed during the morning and evening hours near the city, but around noon at a distance of more than $100 \mathrm{~km}$ away from Paris the concentrations are approximately two times higher. So we assume that the boundary layer influence is small at least for secondary and large scale transported pollutants. The boundary layer influence on primary and locally emitted pollution is however difficult to assess during these types of measurements.

\subsection{Stationary measurements: plume crossing during wind shift}

Measurement example: on 27 July 2009 the wind direction was predicted to shift from South to West during the day. This was no sufficiently stable meteorological condition for a mobile measurement trip, but it was well suited for a MoLa stationary measurement located North-East of Paris at a distance of about $30 \mathrm{~km}$ to the Paris metropolitan area (see Fig. 4). The site was surrounded by open fields with no upwind local pollution sources (e.g. villages, roads) nearby, and so an undisturbed flow of the air masses to the sampling location was given. Due to the wind shift both a measurement of background and emission plume air masses was possible. This wind shift is represented by three wind rose plots in the upper part of Fig. 6. The wind rose plots are centred at the measurement location and the red dots symbolize the direction of Paris in relation to the site. In the morning and late afternoon the measurement site was not affected by urban air masses. However, during the hours around noon the wind direction was shifting, advecting air masses directly from Paris 

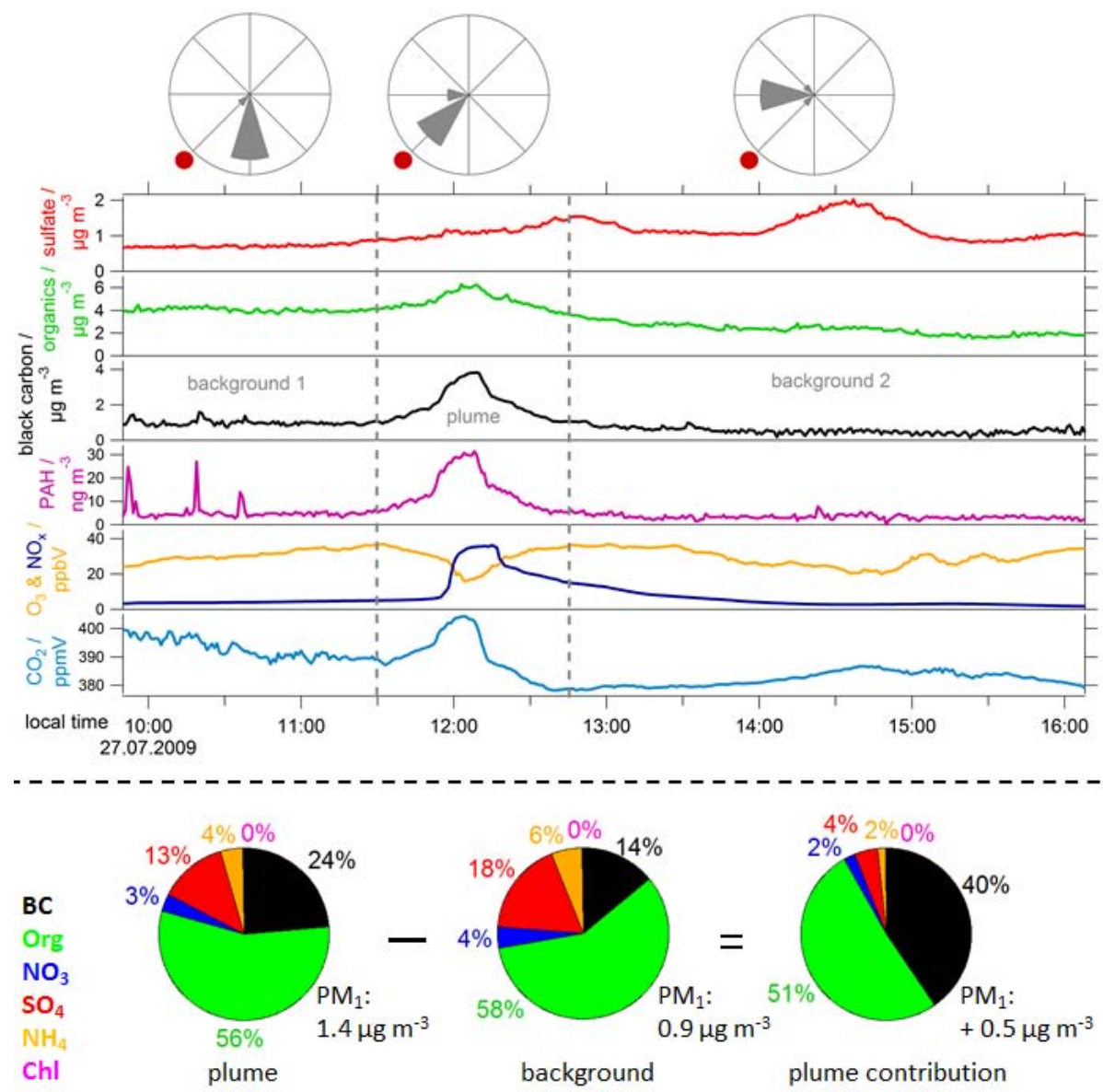

Fig. 6. $\mathrm{CO}_{2}$ (light blue), $\mathrm{O}_{3}$ (yellow) and $\mathrm{NO}_{\mathrm{x}}$ (dark blue) mixing ratios as well as PAH (purple), black carbon (black), particulate organics (green) and sulfate (red) mass concentrations measured during a stationary measurement on 27 July 2009 by MoLa. The measurement location (centre of windrose plots) was in the North-East of Paris (red dot in windrose plots) situated about $30 \mathrm{~km}$ from the city border. The wind was shifting from South to West during the measurement as indicated by the wind rose plots. The grey vertical dashed lines frame the time period when the Paris emission plume was sampled. The time resolution of the data is 1 min. However, internal averaging settings of the $\mathrm{NO}_{\mathrm{x}}$ module caused longer averaging times (several minutes, slightly varying with concentration changes) during this stationary measurement for this instrument. Additionally, the average $\mathrm{PM}_{1}$ aerosol mass concentrations and compositions for plume and background air masses are provided in the lower part of this figure. The total $\mathrm{PM}_{1}$ mass concentration was calculated as the sum of BC (MAAP instrument), Org, $\mathrm{NO}_{3}, \mathrm{SO}_{4}, \mathrm{NH}_{4}$ and $\mathrm{Chl}$ (AMS instrument) concentrations. The subtraction of the average background concentration from the average plume concentration gives the plume contribution to total $\mathrm{PM}_{1}$.

and the emission plume was sampled during the time between the grey dashed lines in Fig. 6.

In Fig. 6 time series of $\mathrm{O}_{3}, \mathrm{NO}_{\mathrm{x}}$ and $\mathrm{CO}_{2}$ mixing ratios as well as black carbon, $\mathrm{PAH}$, particulate organics and sulfate mass concentrations are presented for this scenario. There is a clear enhancement in $\mathrm{CO}_{2}, \mathrm{NO}_{\mathrm{x}}$, black carbon, organics and PAH concentrations around noon caused by the Paris emissions. The concentrations increase about sevenfold compared to background values measured on this day for black carbon, about tenfold for $\mathrm{PAH}$ and about twelvefold for $\mathrm{NO}_{\mathrm{x}}$. The $\mathrm{CO}_{2}$ concentration is increased by about $25 \mathrm{ppmV}$ compared to the lowest values measured on this day by MoLa between 12:30 and 13:00 local time. $\mathrm{O}_{3}$ shows a reduced mixing ratio from a maximum of $37 \mathrm{ppbV}$ to a minimum of $16 \mathrm{ppbV}$ due to high $\mathrm{NO}_{\mathrm{x}}$ concentrations associated with fresh emissions in the Paris area.

In contrast, sulfate concentrations show no significant enhancement during this time. $\mathrm{SO}_{2}$ (not presented in this graph) shows a minor increase during this time period, but has obviously not yet been transformed into sulfate until the arrival of the air masses at the measurement site. A clear enhancement in particulate sulfate can be seen in the afternoon around 14:30 local time on this day. This seems to be longrange transported pollution (e.g. from industrial plants emitting $\mathrm{SO}_{2}$ at larger distance to the measurement site), because no simultaneous enhancement can be seen in black carbon or PAH concentrations. $\mathrm{CO}_{2}$ and $\mathrm{O}_{3}$ show slightly higher (lower) concentrations in the afternoon but with different 
temporal behaviour. The reasons for this could not be identified.

In the lower part of Fig. 6 the average $\mathrm{PM}_{1}$ mass concentrations and compositions for background and plume air masses are presented for this measurement example. The subtraction of the average $\mathrm{PM}_{1}$ background concentration from the average $\mathrm{PM}_{1}$ plume concentration gives the plume contribution to $\mathrm{PM}_{1}$. It can be seen that in plume air masses the fraction of $\mathrm{BC}$ is enhanced $(+10 \%)$, caused by BC emissions in Paris (e.g. from diesel fueled cars). Consequently, the Paris emissions mainly contribute black carbon (about $40 \%$ ) but also organic aerosol (about $51 \%$ ) to the background pollutant burden. The average $\mathrm{PM}_{1}$ mass concentrations are quite low on this day with about $0.9 \mu \mathrm{g} \mathrm{m}^{-3}$ in background air masses. The plume contributes about $0.5 \mu \mathrm{g} \mathrm{m}^{-3}$ to the background pollutant burden - this is more than $50 \%$ of the background $\mathrm{PM}_{1}$ concentration.

In summary, these results provide multiple evidence for an emission plume that is transported away from the megacity and has a clear influence on local air quality of the surrounding regions at a distance of several tens of kilometres away from the city border.

\section{Potential and limitations of mobile measurements for megacity emission plume characterisation}

Benefits of mobile measurements: in the context of detailed investigation of megacity plume emission characteristics, three applications were shown to be of benefit. Crosssection measurements through the emission plume allow investigation of the plume structure, caused mainly by emission source distribution, orographic and meteorological conditions and dilution processes. When performed in different distances to the megacity, additional information about transformation (aging) processes of the plume during transport away from the source can be obtained. Axial trips are beneficial due to their quasi-Lagrangian character. Transformation processes of plume emissions can be studied while the air masses travel away from the city. The spatial extent of an emission plume can be measured by driving as far as the emission plume ranges. Stationary measurement sites can be chosen according to current meteorological conditions and minimum influence by local pollution sources and can be quickly changed if necessary. Measurements far away or upwind of the megacity allow unaffected atmospheric background measurements. Measurement locations downwind of the megacity allow on the other hand investigation of temporal variations of megacity emissions. Stationary measurements in combination with appropriate wind shifting allow studying the plume structure like during a mobile crosssection measurement but with negligible influence of local pollution.

Limitations of mobile measurements due to local pollution contamination: a major issue affecting mobile measurements is local pollution contamination of the data. This local pollution can be analysed separately to obtain emission fluxes of point sources or on-road emission indices. However, if larger scale phenomena like background air masses or extended emission plumes are investigated, these local pollutions have to be removed from the data as much as possible. During on-road measurements high concentrations of fresh emissions can dominate the measured values of substances like black carbon, $\mathrm{PAH}$, particulate organic matter, particle number concentration, $\mathrm{CO}_{2}$ and $\mathrm{NO}_{\mathrm{x}}$. If local pollutant emissions occur only sporadically they can be identified by concentration peaks in the time series from fresh pollution markers like $\mathrm{CO}_{2}$ or $\mathrm{NO}_{\mathrm{x}}$ - provided that the time series have a high temporal resolution (about $1 \mathrm{~s}$ ). Automatic procedures are then suitable for pollution removal. However, automatic removal algorithms are not applicable to each data set, e.g. low time resolution data sets or data sets containing a large density of local contamination so that no individual pollution peaks can be identified. In our case the local pollutant density was too high for automatic pollution removal. The time consuming but more objective video tape analysis method was shown to be most useful for mobile laboratories applied under such conditions, even if not every pollution source can be identified. The application of an on-line contamination recording system (e.g. by pressing a button to note the time stamp of a contamination event) is aspired. The removal of local contamination makes the preparation of mobile data more time consuming, but in most cases it is possible to extract a nearly uncontaminated data set for further analysis.

To largely avoid local pollution contamination during mobile measurements in the lowermost troposphere, a vehicle that is not bound to roads, e.g. a zeppelin, could be applied as mobile laboratory. Then real cross-country measurements at a height of (theoretically) a few metres unaffected by most local pollution sources would be possible.

Limitations due to temporal and spatial characteristics of mobile measurements: another limitation of the described mobile measurements is that they can only provide snap shots of the present situation at a certain location. If the emission plume is changed in its structure and/or direction during the measurement, the measured data will show a distorted picture of the plume. Boundary layer effects can also affect the measurements, e.g. when axial or circular trips always start and end at the same time of the day. The snap shot taken by a mobile laboratory still covers a much wider spatial range than that of a stationary measurement. Here it is useful to combine as many measurements as possible, like stationary measurements at several sites and additional mobile measurements, especially when regional phenomena like the emission plume of megacities are investigated.

Limitations from measurement planning: limitations are also inherent in the quality of forecast maps used for planning of the mobile laboratory deployment. For example, local or regional wind deviations between forecast and actually occurring meteorological conditions can affect the success 
of a mobile measurement. The risk of missing the emission plume due to uncertainties in the forecasts can be reduced by selecting appropriate measurement routes. For this purpose MOSQUITA often performed combinations of cross sections and axial trips to cover a wider area around Paris.

\section{Summary}

We present an overview of mobile aerosol and trace gas measurements carried out in the framework of the European Union FP7 MEGAPOLI project in the greater Paris area. During two major field campaigns, one in summer 2009 and one during winter 2010, mobile and also stationary measurements were carried out deploying the mobile laboratories MoLa and MOSQUITA. The measured variables include aerosol properties like particle number concentration, size distribution and chemical composition as well as concentrations of major trace gases like $\mathrm{O}_{3}, \mathrm{NO}_{\mathrm{x}}, \mathrm{SO}_{2}$ and $\mathrm{CO}_{2}$. Intercomparison exercises of similar devices were performed. Depending on the predicted weather and plume conditions three different measurement strategies were carried out. Axial measurements allowed insight into the spatial extent of the emission plume as well as on transformation processes during its transport away from the city. Cross sections were most useful for differentiation between background and emission plume loadings of the atmosphere and to determine the plume direction and width. Stationary measurements were best suited for unstable weather conditions or as real background measurements outside the influence range of the Paris region and are also not influenced by local pollution. Before further analysis of the data set, the data were carefully treated to remove local contamination. Two advanced analysis methods were used to give an overview of the possible information content of mobile data.

To present the types of applications during the MEGAPOLI field campaigns we showed four measurement examples. These examples demonstrated that the developed and applied measurement and analysis strategies worked well for the investigation of emission plume characteristics. They also showed that the plume emissions were visible in many measurement parameters as expected due to the various emission sources in the Paris metropolitan area. The first example demonstrated the difference between long-range transported and local or regional pollution. Fresh pollution showed rapid concentration changes while aged pollution varied on longer temporal and spatial scales. The second example consisted of a combination of MoLa and MOSQUITA data sets for information about the spatial structure of the Paris emission plume. A clear reduction of the $\mathrm{O} / \mathrm{C}$ ratio of the organic aerosol indicated the emission plume, with the lowest $\mathrm{O} / \mathrm{C}$ values in the lateral core of the plume. The spatial extent of the emission plume - in this example up to about $60 \mathrm{~km}$ from the city border - could be seen in example three, an axial measurement trip carried out during the summer campaign. The last example illustrated the influence of Paris emissions on local air quality at a distance of $30 \mathrm{~km}$ away from the city border. During a stationary measurement the wind shifted, causing the plume to pass over the measurement location, allowing the direct comparison of background and polluted air masses. Here a sevenfold increase of black carbon concentrations, a tenfold increase of PAH concentrations and a twelvefold increase of $\mathrm{NO}_{\mathrm{x}}$ mixing ratios were observed when the plume passed the site.

A critical discussion of the advantages and limitations of mobile measurements in the framework of megacity emission investigations completes this work. Special focus lied on the removal of local contamination, an issue usually not being so severe during stationary measurements, provided that the measurement location has been chosen well. The high scientific potential of mobile measurements is given due to spatial flexibility of the measurement location. Changes in environmental conditions can instantaneously be accounted for by adaption of the measurement route due to online access to the measured data. The emission plume structure and spatial extent can only be reasonably well measured by applying mobile measurements. Limitations are inherent in the still limited spatial range covered by a single mobile laboratory in a certain time and in the uncertainties of the emission plume forecast. To improve the spatial coverage of measurement locations the combination of several mobile laboratories and also fixed measurement sites probably is the best, albeit expensive, approach.

Acknowledgements. The MoLa team (Max Planck Institute for Chemistry, MPI-C) thanks Thomas Böttger, Jovana-Maria Diesch, Katja Dzepina, Johannes Fachinger, Friederike Freutel, Stéphane Gallavardin, Thomas Klimach, Paul Reitz, Anja Roth, Julia Schmale, Johannes Schneider and Sören R. Zorn for support during organisation, preparation and realisation of the measurement campaigns. The Golf Départemental de la Poudrerie (Livry-Gargan, Seine-Saint-Denis) is gratefully acknowledged for hosting the suburb North-East stationary measurement and MoLa parking site. The contribution of Max Planck Institute for Chemistry's scientists to the MEGAPOLI field campaigns and data analysis was fully covered by internal funds of the MPI-C Particle Chemistry Department.

The MOSQUITA team (Paul Scherrer Institute) thanks Claudia Mohr, René Richter and the Paul Scherrer Institute's team working at the suburb South-West measurement site during the campaigns. The contribution of the groups from Paul Scherrer Institute, Laboratoire Inter-universitaire des Systèmes Atmosphériques and Institut National de l'Environnement Industriel et des Risques and the campaign participation was supported by the European Union's Framework Programme FP/2007-2011 within the project MEGAPOLI, grant agreement no. 212520.

Aurélie Colomb at Laboratoire de Météorologie Physique (LaMP), CNRS, Université Blaise Pascal, Aubière, France is acknowledged for providing additional gas phase intercomparison 
data. We also extend our acknowledgement to the technical and computer staff at the South-West suburb measurement site (SIRTA) for taking meteorological observations and making the data set easily accessible.

The service charges for this open access publication have been covered by the Max Planck Society.

Edited by: W. Maenhaut

\section{References}

Aiken, A. C., DeCarlo, P. F., and Jimenez, J. L.: Elemental analysis of organic species with electron ionization high-resolution mass spectrometry, Anal. Chem., 79, 8350-8358, 2007.

Aiken, A. C., DeCarlo, P. F., Kroll, J. H., Huffman, J. A., Docherty, K. S., Ulbrich, I. M., Mohr, C., Kimmel, J. R., Sueper, D., Sun, Y., Zhang, Q., Trimborn, A., Northway, M., Ziemann, P. J., Canagaratna, M. R., Onasch, T. B., Alfarra, M. R., Prévôt, A. S. H., Dommen, J., Duplissy, J., Metzger, A., Baltensperger, U., and Jimenez, J. L.: O/C and OM/OC ratios of primary, secondary, and ambient organic aerosols with high-resolution time-of-flight aerosol mass spectrometry, Environ. Sci. Technol., 42, 44784485, 2008.

Aire urbaine: available at: http://recensement.insee.fr, last access: 15 November 2013.

Akimoto, H.: Global air quality and pollution, Science, 302, 17161719, 2003.

Bahreini, R., Ervens, B., Middlebrook, A. M., Warneke, C., de Gouw, J. A., DeCarlo, P. F., Jimenez, J. L., Brock, C. A., Neuman, J. A., Ryerson, T. B., Stark, H., Atlas, E., Brioude, J., Fried, A., Holloway, J. S., Peischl, J., Richter, D., Walega, J., Weibring, P., Wollny, A. G., and Fehsenfeld, F. C.: Organic aerosol formation in urban and industrial plumes near Houston and Dallas, Texas, J. Geophys. Res., 114, D00F16, doi:10.1029/2008JD011493, 2009.

Beekmann, M., Prévôt, A. S. H., Drewnick, F., Sciare, J., Pandis, S. N., van der Gon, H. A. C. D., Crippa, M., Freutel, F., Poulain, L., Ghersi, V., Rodriguez, E., Beirle, S., Zotter, P., von der WeidenReinmüller, S.-L., Bressi, M., Fountoukis, C., Petetin, H., Szidat, S., Schneider, J., Rosso, A., El Haddad, I., Megaritis, A., Zhang, Q., Slowik, J. G., Moukhtar, S., Kolmonen, P., Stohl, A., Eckhardt, S., Borbon, A., Gros, V., Marchand, N., Jaffrezo, J. L., Schwarzenboeck, A., Colomb, A., Wiedensohler, A., Borrmann, S., Lawrence, M., Baklanov, A., and Baltensperger, U.: Regional emissions control fine particulate matter levels in the Paris Megacity, in preparation, 2014.

Bukowiecki, N., Dommen, J., Prévôt, A. S. H., Richter, R., Weingartner, E., and Baltensperger, U.: A mobile pollutant measurement laboratory - measuring gas phase and aerosol ambient concentrations with high spatial and temporal resolution, Atmos. Environ., 36, 5569-5579, 2002.

Canagaratna, M. R., Jayne, J. T., Jimenez, J. L., Allan, J. D., Alfarra, M. R., Zhang, Q., Onasch, T. B., Drewnick, F., Coe, H., Middelbrook, A., Delia, A., Williams, L. R., Trimborn, A. M., Northway, M. J., DeCarlo, P. F., Kolb, C. E., Davidovits, R., and Worsnop, D. R.: Chemical and microphysical characterization of ambient aerosols with the Aerodyne aerosol mass spectrometer, Mass Spectrom. Rev., 26, 185-222, 2007.
Crippa, M., DeCarlo, P. F., Slowik, J. G., Mohr, C., Heringa, M. F., Chirico, R., Poulain, L., Freutel, F., Sciare, J., Cozic, J., Di Marco, C. F., Elsasser, M., Nicolas, J. B., Marchand, N., Abidi, E., Wiedensohler, A., Drewnick, F., Schneider, J., Borrmann, S., Nemitz, E., Zimmermann, R., Jaffrezo, J.-L., Prévôt, A. S. H., and Baltensperger, U.: Wintertime aerosol chemical composition and source apportionment of the organic fraction in the metropolitan area of Paris, Atmos. Chem. Phys., 13, 961-981, doi:10.5194/acp-13-961-2013, 2013.

Crutzen, P. J.: New Directions: The growing urban heat and pollution "island" effect - impact on chemistry and climate, Atmos. Environ., 38, 3539-3540, 2004.

DeCarlo, P. F., Kimmel, J. R., Trimborn, A., Northway, M. J., Jayne, J. T., Aiken, A. C., Gonin, M., Fuhrer, K., Horvath, T., Docherty, K. S., Worsnop, D. R., and Jimenez, J. L.: Field-deployable, high-resolution, time-of-flight aerosol mass spectrometer, Anal. Chem., 78, 8281-8289, 2006.

Drewnick, F., Hings, S. S., Alfarra, M. R., Prevot, A. S. H., and Borrmann, S.: Aerosol quantification with the Aerodyne Aerosol Mass Spectrometer: detection limits and ionizer background effects, Atmos. Meas. Tech., 2, 33-46, doi:10.5194/amt-2-332009, 2009.

Drewnick, F., Böttger, T., von der Weiden-Reinmüller, S.-L., Zorn, S. R., Klimach, T., Schneider, J., and Borrmann, S.: Design of a mobile aerosol research laboratory and data processing tools for effective stationary and mobile field measurements, Atmos. Meas. Tech., 5, 1443-1457, doi:10.5194/amt-5-1443-2012, 2012.

Elanskii, N. F., Belikov, I. B., Golitsyn, G. S., Grisenko, A. M., Lavrova, O. V., Pankratova, N. V., Safronov, A. N., Skorokhod, A. I., and Shumskii, R. A.: Observations of the atmosphere composition in the Moscow megapolis from a mobile laboratory, Dokl. Earth Sci., 432, 649-655, 2010.

Fenger, J.: Urban air quality, Atmos. Environ., 33, 4877-4900, 1999.

Freutel, F., Schneider, J., Drewnick, F., von der Weiden-Reinmüller, S.-L., Crippa, M., Prévôt, A. S. H., Baltensperger, U., Poulain, L., Wiedensohler, A., Sciare, J., Sarda-Estève, R., Burkhart, J. F., Eckhardt, S., Stohl, A., Gros, V., Colomb, A., Michoud, V., Doussin, J. F., Borbon, A., Haeffelin, M., Morille, Y., Beekmann, M., and Borrmann, S.: Aerosol particle measurements at three stationary sites in the megacity of Paris during summer 2009: meteorology and air mass origin dominate aerosol particle composition and size distribution, Atmos. Chem. Phys., 13, 933-959, doi:10.5194/acp-13-933-2013, 2013.

Gros, V., Sciare, J., and Yu, T.: Air-quality measurements in megacities: Focus on gaseous organic and particulate pollutants and comparison between two contrasted cities, Paris and Beijing, C. R. Geosci., 339, 764-774, 2007.

Gurjar, B. R. and Lelieveld, J.: New Directions: Megacities and global change, Atmos. Environ., 39, 391-393, 2005.

Harrison, R. M., Yin, J., Tilling, R. M., Cai, X., Seakins, P. W., Hopkins, J. R., Lansley, D. L., Lewis, A. C., Hunter, M. C., Heard, D. E., Carpenter, L. J., Creasey, D. J., Lee, J. D., Pilling, M. J., Carslaw, N., Emmerson, K. M., Redington, A., Derwent, R. G., Ryall, D., Mills, G., and Penkett, S. A.: Measurement and modelling of air pollution and atmospheric chemistry in the U.K. West Midlands conurbation: Overview of the PUMA consortium project, Sci. Total Environ., 360, 5-25, 2006. 
Honoré, C., Rouïl, L., Vautard, R., Beekmann, M., Bessagent, B., Dufour, A., Elichegaray, C., Flaud, J.-M., Malherbe, L., Meleux, F., Menut, L., Martin, D., Peuch, A., Peuch, V.-H., and Poisson, N.: Predictability of European air quality: Assessment of 3 years of operational forecasts and analyses by the PREV'AIR system, J. Geophys. Res., 113, D04301, doi:10.1029/2007JD008761, 2008.

Jayne, J. T., Leard, D. C., Zhang, X., Davidovits, P., Smith, K. A., Kolb, C. E., and Worsnop, D. R.: Development of an aerosol mass spectrometer for size and composition analysis of submicron particles, Aerosol Sci. Tech., 33, 49-70, 2000.

Jimenez, J. L., Canagaratna, M. R., Donahue, N. M., Prévôt, A. S. H., Zhang, Q., Kroll, J. H., DeCarlo, P. F., Allan, J. D., Coe, H., Ng, N. L., Aiken, A. C., Docherty, K. S., Ulbrich I. M., Grieshop, A. P., Robinson, A. L., Duplissy, J., Smith, J. D., Wilson, K. R., Lanz, V. A., Hueglin, C., Sun, Y. L., Tian, J., Laaksonen, A., Raatikainen, T., Rautianinen, J., Vaattovaara, P., Ehn, M., Kulmala, M., Tomlinson, J. M., Collins, D. R., Cubison, M. J., Dunlea, E. J., Huffman, J. A., Onasch, T. B., Alfarra, M. R., Williams, P. I., Bower, K., Kondo, Y., Schneider, J., Drewnick, F., Borrmann, S., Weimer, S., Demerjian, K., Salcedo, D., Cottrell, L., Griffin, R., Takami, A., Miyoshi, T., Hatakeyama, S., Shimono, A., Sun, J. Y., Zhang, Y. M., Dzepina, K., Kimmel, J. R., Sueper, D., Jayne, J. T., Herndon, S. C., Trimborn, A. M., Williams, L. R., Wood, E. C., Middlebrook, A. M., Kolb, C. E., Baltensperger, U., and Worsnop, D. R.: Evolution of organic aerosol in the atmosphere, Science, 326, 1525-1529, 2009.

Kolb, C. E., Herndon, S. C., McManus, J. B., Shorter, J. H., Zahniser, M. S., Nelson, D. D., Jayne, J. T., Canagaratna, M. R., and Worsnop, D. R.: Mobile laboratory with rapid response instruments for real-time measurements of urban and regional trace gas and particulate distributions and emission source characteristics, Environ. Sci. Technol., 38, 5694-5703, 2004.

Kunkel, D., Lawrence, M. G., Tost, H., Kerkweg, A., Jöckl, P., and Borrmann, S.: Urban emission hot spots as sources for remote aerosol deposition, Geophys. Res. Lett., 39, L01808, doi:10.1029/2011GL049634, 2012.

Lanz, V. A., Alfarra, M. R., Baltensperger, U., Buchmann, B., Hueglin, C., and Prévôt, A. S. H.: Source apportionment of submicron organic aerosols at an urban site by factor analytical modelling of aerosol mass spectra, Atmos. Chem. Phys., 7, 15031522, doi:10.5194/acp-7-1503-2007, 2007

Lanz, V. A., Prévôt, A. S. H., Alfarra, M. R., Weimer, S., Mohr, C., DeCarlo, P. F., Gianini, M. F. D., Hueglin, C., Schneider, J., Favez, O., D’Anna, B., George, C., and Baltensperger, U.: Characterization of aerosol chemical composition with aerosol mass spectrometry in Central Europe: an overview, Atmos. Chem. Phys., 10, 10453-10471, doi:10.5194/acp-10-10453-2010, 2010.

Matthew, B. M., Middlebrook, A. M., and Onasch, T. B.: Collection efficiencies in an Aerodyne Aerosol Mass Spectrometer as a function of particle phase for laboratory generated aerosols, Aerosol Sci. Tech., 42, 884-898, 2008.

McMurry, P.: A review of atmospheric aerosol measurements, Atmos. Environ., 34, 1959-1999, 2000.

MEGAPOLI Project: available at: http://megapoli.info, last access: 15 November 2013.

Mobile Laboratory MOSQUITA: available at: http://psi.ch/lac/ mobile-laboratory, last access: 15 November 2013.
Mohr, C., Richter, R., DeCarlo, P. F., Prévôt, A. S. H., and Baltensperger, U.: Spatial variation of chemical composition and sources of submicron aerosol in Zurich during wintertime using mobile aerosol mass spectrometer data, Atmos. Chem. Phys., 11, 7465-7482, doi:10.5194/acp-11-7465-2011, 2011.

Mohr, C., DeCarlo, P. F., Heringa, M. F., Chirico, R., Slowik, J. G., Richter, R., Reche, C., Alastuey, A., Querol, X., Seco, R., Peñuelas, J., Jiménez, J. L., Crippa, M., Zimmermann, R., Baltensperger, U., and Prévôt, A. S. H.: Identification and quantification of organic aerosol from cooking and other sources in Barcelona using aerosol mass spectrometer data, Atmos. Chem. Phys., 12, 1649-1665, doi:10.5194/acp-12-1649-2012, 2012.

Molina, M. J. and Molina, L. T.: Megacities and atmospheric pollution, J. Air Waste Manage. Assoc., 54, 644-680, 2004.

Nunnermacker, L. J., Imre, D., Daum, P. H., Kleinman, L., Lee, Y.N., Lee, J. H., Springston, S. R., Newman, L., Weinstein-Lloyd, J., Luke, W. T., Banta, R., Alvarez, R., Senff, C., Sillman, S., Holdren, M., Keigley, G. W., and Zhou, X.: Characterization of the Nashville urban plume on July 3 and July 18, 1995, J. Geophys. Res., 103, 28129-28148, doi:10.1029/98JD01961, 1998.

Paatero, P.: Least squares formulation of robust non-negative factor analysis, Chemometr. Intell. Lab., 37, 23-35, 1997.

Paatero, P. and Tapper, U.: Positive matrix factorization: a nonnegative factor model with optimal utilization of error estimated of data values, Environmetrics, 5, 111-126, 1994.

Pey, J., Rodriguez, S., Querol, X., Alastuey, A., Moreno, T., Putaud, J. P., and van Dingenen, R.: Variations of urban aerosols in the western Mediterranean, Atmos. Environ., 42, 9052-9062, 2008.

Pirjola, L., Parviainen, H., Hussein, T., Valli, A., Hämeri, K., Aaalto, P., Virtanen, A., Keskinen, J., Pakkanen, T. A., Mäkelä, T., and Hillamo, R. E.: "Sniffer" - a novel tool for chasing vehicles and measuring traffic pollutants, Atmos. Environ., 38, 36253635, 2004.

Prev'Air: available at: http://prevair.org, last access: 15 November 2013.

Raga, G. B., Castro, T., and Baumgardner, D.: The impact of megacity pollution on local climate and implications for the regional environment: Mexico City, Atmos. Environ., 35, 1805-1811, 2001.

Royer, P., Chazette, P., Sartelet, K., Zhang, Q. J., Beekmann, M., and Raut, J.-C.: Comparison of lidar-derived $\mathrm{PM}_{10}$ with regional modeling and ground-based observations in the frame of MEGAPOLI experiment, Atmos. Chem. Phys., 11, 1070510726, doi:10.5194/acp-11-10705-2011, 2011.

SAFIRE: available at: http://www.safire.fr/web/index.php, last access: 15 November 2013.

Seakins, P. W., Lansley, D. L., Hodgson, A., Huntley, N., and Pope, F.: New Directions: Mobile laboratory reveals new issues in urban air quality, Atmos. Environ., 36, 1247-1248, 2002.

Steinbacher, M., Zellweger, C., Schwarzenbach, B., Bugmann, S., Buchmann, B., Ordóñez, C., Prévôt, A. S. H., and Hueglin, C. Nitrogen oxide measurements at rural sites in Switzerland: Bias of conventional measurement techniques, J. Geophys. Res., 112, D11307, doi:10.1029/2006JD007971, 2007.

Sun, J., Zhang, Q., Canagaratna, M. R., Zhang, Y., Ng, N. L., Sun, Y., Jayne, J. T., Zhang, X., Zhang, X., and Worsnop, D. R.: Highly time- and size-resolved characterization of submicron aerosol particles in Beijing using an Aerodyne Aerosol Mass Spectrometer, Atmos. Environ., 44, 131-140, 2010. 
ToF-AMS Analysis Software Homepage: available at: http://cires.colorado.edu/jimenez-group/wiki/index.php/

ToF-AMS_Analysis_Software, last access: 15 November 2013.

Ulbrich, I. M., Canagaratna, M. R., Zhang, Q., Worsnop, D. R., and Jimenez, J. L.: Interpretation of organic components from Positive Matrix Factorization of aerosol mass spectrometric data, Atmos. Chem. Phys., 9, 2891-2918, doi:10.5194/acp-9-2891-2009, 2009.

United Nations: World Urbanization Prospects: The 2011 Revision, available at: http://esa.un.org/unpd/wup/index.htm (last access: 15 November 2013), New York, 2012.

United Nations: World Populations Prospects: The 2012 Revision, available at: http://esa.un.org/unpd/wpp/index.htm (last access: 15 November 2013), New York, 2013.

von der Weiden, S.-L., Drewnick, F., and Borrmann, S.: Particle Loss Calculator - a new software tool for the assessment of the performance of aerosol inlet systems, Atmos. Meas. Tech., 2, 479-494, doi:10.5194/amt-2-479-2009, 2009.

von der Weiden-Reinmüller, S.-L., Drewnick, F., Zhang, Q. J., Freutel, F., Beekmann, M., and Borrmann, S.: Megacity emission plume characteristics in summer and winter investigated by mobile aerosol and trace gas measurements: The Paris metropolitan area, Atmos. Chem. Phys. Discuss., submitted, 2013.
Weimer, S., Mohr, C., Richter, R., Keller, J., Mohr, M., Prévôt, A. S. $\mathrm{H}$., and Baltensperger, U.: Mobile measurements of aerosol number and volume size distributions in an Alpine valley: influence of traffic versus wood burning, Atmos. Environ., 43, 624-630, 2009.

Zhang, Q., Worsnop, D. R., Canagaratna, M. R., and Jimenez, J. L.: Hydrocarbon-like and oxygenated organic aerosols in Pittsburgh: insights into sources and processes of organic aerosols, Atmos. Chem. Phys., 5, 3289-3311, doi:10.5194/acp-5-32892005, 2005.

Zhang, Q., Jimenez, J. L., Canagaratna, M. R., Ulbrich, I. M., Ng, N. L., Worsnop, D. R., and Sun, Y.: Understanding atmospheric organic aerosols via factor analysis of aerosol mass spectrometry: a review, Anal. Bioanal. Chem., 401, 3045-3067, 2011. 